\title{
Loss of leaf-out and flowering synchrony under global warming
}

6 Affiliations:

$7 \quad{ }^{1}$ Institute of Integrative Biology, ETH Zurich (Swiss Federal Institute of Technology),

8 Universitätsstrasse 16, 8092 Zurich, Switzerland

$9 \quad{ }^{2}$ Systematic Botany and Mycology, Department of Biology, University of Munich (LMU), 80638

10 Munich, Germany

11

$12 *$ Author for correspondence: constantin.zohner@t-online.de

13

14 Keywords: Climate change | Phenology | Temperate plants | Flowering | Leaf unfolding | Day-

15 length | Chilling

16

17

18

19

20

21

22

23 


\section{Abstract}

26 The temporal overlap of phenological stages, phenological synchrony, crucially influences

27 ecosystem functioning. For flowering, among-individual synchrony influences gene flow. For

28 leaf-out, it affects interactions with herbivores and competing plants. If individuals differ in their

29 reaction to the ongoing change in global climate, this should affect population-level synchrony.

30 Here, we use climate-manipulation experiments, Pan-European long-term ( $>15$ years)

31 observations, and common garden monitoring data on up to 72 woody and herbaceous species to

32 study the effects of increasing temperatures on the extent of within-population leaf-out and

33 flowering synchrony. Warmer temperatures reduce in situ leaf-out and flowering synchrony by

34 up to $55 \%$, and experiments on European beech provide a mechanism for how individual genetic

35 differences may explain this finding. The rapid loss of reproductive and vegetative synchrony in

36 European plants predicts changes in their gene flow and trophic interactions, but community-

37 wide consequences remain largely unknown. 
49 The structure and functioning of ecosystems crucially depends on the timing of annually repeated

50 life stages, such as leaf-out and flowering (1-4). Anthropogenic climate warming is causing

51 advanced leaf-out and flowering in both herbs and trees, and this is affecting growth and

52 reproductive success (5-8). Warmer springs and summers are also causing leaf-out and flowering

53 to spread out over longer periods because the sensitivity to winter chilling, spring warming, and

54 day length differs among species $(2,3,9-11)$. Such species-specific responses imply variation in

55 heritable phenological strategies among individuals, but how current climate warming is shifting

56 within-population phenology and possibly synchrony has not been addressed. For leaf-out, inter-

57 individual synchrony affects interactions with foliovores and competing plants (12). For

58 flowering, reduced inter-individual synchrony should adversely affect gene flow by reducing

59 cross-pollination and fruit set (13). To detect such possible effects of climate warming on within-

60 population synchrony, a range of herbs and trees, representing different leaf-out and flowering

61 strategies, needs to be studied.

62 Here, we use a combination of climate-manipulation experiments, common garden

63 monitoring, and long-term Central European in situ observations to analyze effects of warming

64 on within-population phenological synchrony. The long-term data were obtained from the Pan

65 European Phenology Project (http://www.pep725.eu, hereafter PEP). The PEP data consisted of

6612,536 individual time series (each minimally 15 years long), comprising the leaf-out times of

67 nine dominant tree species and the flowering times of six tree species, four shrubs, and five herbs

68 (see Methods and the distribution of the sites in Fig. 1a, and Figs. S1 and S2). To define

69 populations, we divided the study area into pixels of one-degree resolution $(\sim 110 \times 85 \mathrm{~km})$ and

70 then calculated leaf-out synchrony (LOS) and flowering synchrony (FLS) in a given year as the

71 standard deviation of leaf-out or flowering date for all individuals within a pixel (note that the

72 data were cleaned to ensure that observed individuals were the same between years; see 
73 Methods). For each pixel and each phenological stage (leaf-out or flowering), we determined the

74 preseason as the period 60 days before the average leaf unfolding or flowering date within the

75 respective pixel.

76

As expected, within pixels, species' mean leaf-out dates were negatively correlated with

77 preseason temperature $(98 \%$ of observation series statistically significant at $P<0.05)$, with a

78 mean linear correlation coefficient of $-0.76 \pm 0.03$ (mean $\pm 95 \%$ confidence interval), predicting

79 an average advance of $4.3 \pm 0.2$ days per each degree warming. Similarly, in more than $99 \%$ of

80 pixels, the mean flowering dates were negatively correlated with the preseason temperature $(91 \%$

81 statistically significant at $P<0.05$ ), with a mean linear correlation coefficient of $-0.75 \pm 0.10$,

82 predicting an average advance of $4.6 \pm 0.2$ days per each degree warming.

83 Surprisingly, higher preseason temperatures had a negative effect on LOS in eight of the

84 nine species (Figs. 1c and S1) and on FLS in 10 out of 15 species (Figs. 1d and S2). None of the

85 species exhibited a positive effect. Across all species, preseason temperature negatively affected

86 LOS in $78 \%$ of analyzed pixels $(15 \%$ statistically significant at $P<0.05)$, i.e., the standard

87 deviation of inter-individual leaf-out times increased by $0.45 \pm 0.07$ (mean $\pm \mathrm{CI}$ ) days per degree

88 of warming, with a mean linear correlation coefficient of $0.19 \pm 0.03$. Significant positive effects

89 of preseason temperature on LOS appeared in fewer than $1 \%$ of pixels. The species showing the

90 strongest decline in LOS related to warmer preseason temperatures was European beech (Fagus

91 sylvatica; Fig. 1a): preseason temperature negatively affected LOS in $95 \%$ of analyzed pixels

92 (39\% statistically significant), with the standard deviation of inter-individual leaf-out times

93 increasing by $0.61 \pm 0.05$ days per degree of warming (Fig. 1b) and a mean linear correlation

94 coefficient of $0.37 \pm 0.06$. When modelling the distribution of within-population leaf-out dates

95 under different preseason temperatures, we found that warming increases the inter-individual 
96 variation in leaf-out times by up to $55 \%$, which equates to lengthening the period during which

$9795 \%$ of individuals in a population leaf-out by 11 days (Figs. 1e and S3).

99 pixels (18\% statistically significant), with the standard deviation of inter-individual flowering

100 times increasing by $0.35 \pm 0.15$ days per degree of warming and a mean linear correlation

101 coefficient of $0.15 \pm 0.06$ (Figs. 1d and S2a). A significant positive effect of preseason

102 temperature on FLS was found in only $2 \%$ of pixels. The species showing the strongest decline in

103 FLS related to warmer preseason temperatures was the European alder (Alnus glutinosa):

104 preseason temperature negatively affected FLS in $91 \%$ of analyzed pixels (33\% statistically

105 significant), with the standard deviation of inter-individual flowering times increasing by $0.91 \pm$

1060.27 days per degree of warming and a mean linear correlation coefficient of $0.30 \pm 0.08$. When

107 modelling the distribution of within-population flowering dates under different preseason

108 temperatures, we found that warming increases leaf-out variation by up to $51 \%$, which equates to

109 lengthening the period during which $95 \%$ of individuals in a population initiate flowering by 23

110 days (Figs. 1f and S4). In species, such as the crocus Colchicum autumnale and the heath Calluna

111 vulgaris, where preseason temperature had little effect on the mean flowering date, preseason

112 temperature also had little effect on FLS (Figs. S4 and S7).

113 To cross-validate the results obtained from the PEP data, we used common garden data

114 consisting of leaf-out information on 209 individuals in 59 temperate woody species (minimally

1153 individuals per species) observed in the Munich Botanical garden from 2013 to 2018. A

116 Bayesian hierarchical model, including preseason temperature as predictor variable, the standard

117 deviation of inter-individual leaf-out times per year as response variable, and species as a random

118 effect, showed a significantly negative effect of preseason temperature on LOS (lower panel Fig. 
119 2a). On average, across all 59 species, the standard deviation of inter-individual leaf-out times

120 increased by $0.26 \pm 0.10($ mean $\pm \mathrm{CI})$ days per degree of warming.

121 Which factors cause the loss of inter-individual synchrony under climate warming? One

122 possibility is that individuals reach their forcing sums required for leaf-out or flowering over a

123 longer period because "within-spring warming speed" may be decreasing, flattening the

124 temperature curve during spring $(14,15)$. Thus, while the time span among individual leaf-out

125 times might increase, differences in the forcing sums required until leaf-out or flowering among

126 individuals might remain similar. To test this, we additionally calculated leaf-out/flowering

127 synchrony as the standard deviation in individual forcing requirements (degree-days [DD] from 1

128 January until leaf-out/flowering) [hereafter referred to as LOS-DD and FLS-DD] for both the

129 PEP and Munich common garden data. In both data sets, we found a strong (albeit slightly

130 weaker compared to the LOS/FLS analysis) negative relationship between preseason temperature

131 and LOS-DD, i.e., individual differences in the forcing sums required until leaf-out or flowering

132 are increasing with warmer preseasons (Figs. 2a and S6). We also simulated synchrony of spring

133 phenology based on the Munich Jan-May temperatures over the past 60 years, assuming that

134 phenology is solely driven by degree-day accumulation (no effect of photoperiod or winter

135 chilling; see Fig. S5b) and this simulation revealed small losses of synchrony $\left(R^{2}\right.$ values between

1360.04 and 0.11 and regression coefficients between 0.15 and 0.43 , see Fig. S5c). Together, those

137 results show that a flattening temperature curve during spring can account for only a minor

138 proportion of the declining inter-individual synchrony in the 72 species analyzed here.

139 Warmer preseasons in spring are associated with both reduced accumulation of winter

140 chilling and shorter day-lengths at spring onset, and previous experiments on plant phenological

141 strategies have shown pronounced differences among species in their reactions to day length and

142 winter chilling (9-11). To test whether similar differences within species might explain the 
143 decrease in LOS and FLS under climate warming detected in our in-situ data, we designed

144 experiments in which we exposed trees to different regimes of spring warming, winter chilling,

145 and day length. We additionally tested for the relative effects of winter chilling and day length on

146 LOS and FLS using the PEP and Munich common garden data (for each year and individual, we

147 calculated the winter chilling experienced until leaf-out and the day length for the date when an

148 individual's average forcing requirement had been reached).

149 A first experiment addressed inter-individual variation in spring warming ('forcing'),

150 day length, and winter chilling requirements in 11 mature Fagus sylvatica trees grown in the

151 vicinity of the botanical garden in Munich. Twigs were cut at three dormancy stages during

152 winter and exposed to different day-length regimes (8 h, 12 h, or $16 \mathrm{~h}$ light per day) and ambient

153 spring-forcing conditions (mean daily temperature of $16^{\circ} \mathrm{C}$ ). Note that in beech, leaf-out and

154 flowering occur simultaneously because leaves and flowers are located on the same preformed

155 shoots within overwintering buds. The results showed large differences in forcing and day-length

156 requirements among individuals (Fig. 3a and b): for example, while in individual 1, day length

157 had no effect on the amount of warming required until budburst, in individual 11, warming

158 requirements were $>2 \mathrm{x}$ lower under long-day than under short-day conditions (Fig. 3b). Chilling

159 requirements differed little among individuals (compare slopes in Fig. 3c).

160 In a second experiment, we cut twigs of the same 11 beech trees at eight dormancy

161 stages during winter and exposed them to natural day length. Temperatures were the same as in

162 experiment 1, i.e., ambient. This allowed us to determine (i) the extent to which differential

163 reliance on forcing, photoperiod, and winter chilling (as inferred from experiment 1) explains

164 LOS/FLS under natural light conditions, and (ii) the effect of warmer winter and spring

165 conditions on LOS/FLS. As in the in situ data from the Pan European Phenology network,

166 synchrony strongly decreased under warmer spring conditions (Fig. 4 a, b), likely because of day- 
167 length sensitivity differences among individuals (as documented for F. sylvatica; Fig. 3b): Under

168 cold winter conditions, days are already long when spring warming occurs, reducing the effect of

169 a tree's day length sensitivity on its leaf-out time, whereas with early spring warming, days are

170 still short, preventing day-length sensitive trees from budburst. In natural populations, leaf-out

171 advancement in day length-sensitive individuals, but not in day length-insensitive individuals,

172 will thus increase the period of leaf-out under short day conditions. Both the experimental and the

173 PEP in situ data confirm this idea, showing that (i) phenological variation among individuals

174 strongly decreases under short day conditions (Figs. 2b and 3b) and (ii) genetic differences in

175 day-length requirements are the single most important factor explaining variation in budburst

176 times (Fig. 4c, d).

177 This insight explains why, especially in Fagus sylvatica, in which day length has the

178 most pronounced effect on spring phenology $(10,11)$, LOS is strongly affected by preseason

179 temperatures (Fig. 1c). By contrast, in day-length insensitive species, such as silver birch Betula

180 pendula and Norway spruce Picea abies (11), preseason warming has a smaller (but still

181 significant) effect on LOS, suggesting that heritable differences in day-length sensitivity are a

182 major driver of within-population phenological variation. In our common garden data, the

183 standard deviation of inter-individual leaf-out times increased by $0.09 \pm 0.02$ (mean $\pm \mathrm{CI})$ days

184 per decrease in one chilling day, and the standard deviation of inter-individual forcing

185 requirements increased by $0.23 \pm 0.06$ degree-days per decrease in one chilling day (lower panel

186 Fig. 2b), indicating that individual differences in the sensitivity to winter chilling also contribute

187 to the observed loss of phenological synchrony under climate warming.

188 What biological consequences can be expected from less synchronized leaf-out and

189 flowering of the individuals of a species? With regard to vegetative development, 
190 precocious leaf unfolding under warm springs increases the risk of late frost damage (16-18), but

191 also potential carbon gain due to earlier photosynthetic activity (19). This risk-return trade-off

192 will affect selection on suitable genotypes under future conditions, and the increasing spread of

193 leaf-out should increase the selective importance of spring phenology. Whether opportunistic

194 phenological strategies (relying on temperature as the main trigger) or conservative strategies

195 (relying on day length and/or winter chilling as a buffer against highly variable spring

196 temperatures) will be favored in the future will be region-specific, depending on the relative

197 advancement rates of spring warming and late frost events. In continental regions, where the

198 advent of spring is relatively invariable (low late frost risk), phenological strategies reliant on

199 temperature should be favored (20).

200 With regard to flowering, decreased synchrony among individuals, as already strongly

201 evident in Alnus glutinosa (Fig. 1f), should lead to reduced inter-individual pollen transfer.

202 Strong divergence in flowering times among individuals also might lead to assortative mating

203 (depending on incompatibility systems), possibly promoting local adaptation (21-23) and should

204 act as a buffer against climate change-induced phenological mismatch between plants and leaf-

205 feeding or pollen-collecting insects (24). Rapid adaptive responses, for instance a filtering out of

206 extreme phenotypes through increased mortality or reduced reproduction, might counteract

207 warming-induced losses of inter-individual synchrony. Such selection of the standing variation

208 can occur very rapidly, at least in herbaceous plants (25).

209 While our results show that climate warming causes a loss of phenological synchrony

210 among the individuals of a population, a study of leaf-out along elevational gradients in four

211 European tree species, between 1960-2016, revealed that leaf-out times at higher and lower

212 elevations are today compressed into a shorter time window compared to 58 years ago (26).

213 These findings do not contradict those of the present study because populations growing at high 
214 elevations were able to advance their phenology more than those at lower elevations for which

215 chilling and/or day-length requirements are no longer fulfilled (Fig. S8). As a result, the leaf-out

216 times of high- and low-elevation populations are converging (26). At the same time, however,

217 differences in day-length sensitivity (as well as chilling and temperature sensitivity) among the

218 individuals at any one elevation under climate warming are resulting in diverging flowering and

219 leaf-out times.

220 The overall prediction from the present findings is that human-caused climate warming is

221 leading to plant phenologies that are more heterogeneous within populations and more uniform

222 among populations (over altitude or latitude). The rapid loss of reproductive and vegetative

223 synchrony in European plants also predicts changes in their gene flow and trophic interactions,

224 although community-wide consequences are presently unknown.

\section{Conclusion}

227 The synchrony of developmental stages among organisms is a critical aspect of ecosystem

228 functioning. Here, based on massive ground observations and climate-manipulation experiments,

229 we show that global warming is altering within-population synchrony of leaf-out and flowering

230 dates in temperate plants, with warmer temperatures reducing inter-individual synchrony by up to

$23155 \%$. Experiments suggest that individual genetic differences in the sensitivity to day-length

232 and/or winter chilling underlie the loss of synchrony, and future climate warming is expected to

233 further strengthen this trend. These results predict consequences for gene flow and trophic

234 interactions, but also emphasize the importance of adaptation when forecasting future plant

235 growth and productivity. 


\section{Materials and Methods}

240 Analysis of leaf-out and flowering synchrony (LOS and FLS) using the PEP database

241 Data sets. In situ phenological observations were obtained from the Pan European Phenology

242 network (http://www.pep725.eu/), which provides open-access European phenological data.

243 Leaf-out dates were analyzed for 9 species, flowering dates for 15. Data from Germany, Austria,

244 and Switzerland were used for the analysis. For the angiosperm woody species, leaf-out was

245 defined as the date when unfolded leaves, pushed out all the way to the petiole, were visible on

246 the respective individual $(\mathrm{BBCH} 11$, Biologische Bundesanstalt, Bundessortenamt und

247 Chemische Industrie). For the two conifers Larix decidua and Picea abies leaf-out was defined as

248 the date when the first needles started to separate ("mouse-ear stage"; BBCH 10). Flowering was

249 defined as the date of beginning of flowering (BBCH 60). We removed (i) individuals, for which

250 the standard deviation of phenological observations across years was higher than 25 and (ii) leaf-

251 out and flowering dates that deviated from an individual's median more than 3 times the median

252 absolute deviation (moderately conservative threshold) (26).

253 Analysis. To test for an effect of spring temperature on inter-individual leaf-out synchrony (LOS)

254 and flowering synchrony (FLS), we divided the study area into pixels of one degree resolution

$255(\sim 110 \times 85 \mathrm{~km})$, an area that can reasonably be considered as reflecting populations, at least for

256 wind-pollinated woody species (see discussion on herbs in the main text). To allow for within-

257 pixel comparisons of LOS and FLS between years, data from the same individuals had to be used

258 each year. To achieve this, we kept only pixels for which there were at least three individuals

259 with data for the same 15 years. For each pixel, we deleted all (i) individuals growing at altitudes

260 that deviated by $>200 \mathrm{~m}$ from the average altitude of all individuals within the pixel, and (ii)

261 years that had less than $90 \%$ plant-coverage, i.e., data from at least $90 \%$ of the individuals within 
262 the pixel had to be available for the respective year, otherwise the year was excluded from the

263 analysis. This data cleaning left us with a total of 12,536 individuals, 317,672 phenological

264 observations (individuals x year), and a median time-series length of 25 years (minimally 15

265 years, maximally 48 years). The number of individuals within pixels (per species and

266 phenological stage) ranged between 3 and 53 (median = 12). See Figs. S1b and S2b for

267 information on the number of pixels used per species.

268 For each year and species, LOS and FLS within pixels were then calculated as the

269 standard deviation of leaf-out or flowering dates. Additionally, we calculated the standard

270 deviation of forcing requirements among individuals (subsequently referred to as LOS-DD [leaf-

271 out synchrony degree-days] and FLS-DD [flowering synchrony degree-days]) to test if greater

272 phenological variation among individuals can be explained by increasing variation in forcing

273 requirements. Individual forcing requirements until leaf-out were calculated as the sum of degree-

274 days (DD) from 1 January until leaf-out or flowering using $5^{\circ} \mathrm{C}$ as base temperature (e.g., ref.

275 27):

276

$$
D D_{\text {sum }}(t)=\sum_{t o}^{t_{L O}} T_{t}-5
$$

277 where $D D_{\text {sum }}$ is the accumulated degree days until leaf unfolding, $t_{L O}$ is the day of leaf unfolding, $278 T_{t}$ is the mean daily temperature on day $t$, and $t_{0}$ is the start date for forcing accumulation, which 279 was fixed at 1 January. For each year and species, LOS-DD and FLS-DD within pixels were then 280 calculated as the standard deviation of forcing requirements until leaf-out or flowering dates.

281 The daily mean air temperature at each site was derived from a gridded climatic data set

282 of daily mean temperature at $0.5^{\circ}$ spatial resolution (approximately $50 \mathrm{~km}$, ERA-WATCH) (28).

283 For each year, preseason temperature within pixels was defined as the average temperature

284 during the 60 days prior to the average leaf unfolding or flowering date within the respective 
285 pixel, which is the period for which the correlation coefficient between phenological event and

286 temperature is highest (29).

To test if shortened photoperiods and/or reduced winter chilling explain the decrease in

288 phenological synchrony under warmer preseasons, for each year, pixel, and species, we

289 calculated the average chilling hours until leaf-out or flowering and the average photoperiod (PP)

290 at the date when the average forcing requirements until leaf-out or flowering were fulfilled.

291 Chilling hours were calculated on basis of 6-hourly temperature data (CRU-NCEP, spatial

292 resolution of $0.5^{\circ}$; https://crudata.uea.ac.uk/cru/data/ncep/), as the sum of hours from 1

293 November until leaf-out/flowering with an average temperature between $0^{\circ} \mathrm{C}$ and $5^{\circ} \mathrm{C}$ (e.g., ref 294 29):

$$
C h_{s u m}(t)=\sum_{t o}^{t_{L O}} 1 \text { if } 0 \leq T_{t} \leq 5
$$

296 where $C h_{\text {sum }}$ is the sum of chilling hours until leaf unfolding, $t_{L O}$ is the day of leaf unfolding, $T_{t}$ is

297 the hourly mean temperature on hour $t$, and $t_{0}$ is the start date for chilling accumulation, which

298 was fixed at 1 November in the year before leaf unfolding.

299 PP was calculated as a function of latitude and DOY (30):

300

301

$$
\mathrm{PP}=24-\frac{24}{\pi} \cos ^{-1}\left[\frac{\sin \frac{0.8333 \pi}{180}+\sin \frac{L \pi}{180} \sin \varphi}{\cos \frac{L \pi}{180} * \cos \varphi}\right]
$$

$$
\varphi=\sin ^{-1}(0.29795 * \cos \theta)
$$

$$
\theta=0.2163108+2 * \tan ^{-1}(0.9671396 * \tan (0.0086 *(D O Y-186)))
$$

where $L$ is the latitude of the phenological site. 
308 Statistical analyses.

309 Within each pixel we applied linear models to test for an effect of preseason temperature,

310 photoperiod, and winter chilling on phenological synchrony (LOS, LOS-DD, FLS and FLS-DD).

311 We then determined the frequency distributions for the correlation coefficients between

312 phenological synchrony and preseason temperature across all species and sites. For each species,

313 we applied $t$-tests to detect whether the average of all correlation coefficients obtained for each

314 pixel differs from zero. To model changes in the distribution of within-population leaf-out and

315 flowering dates (means and standard deviations) in response to temperature, we applied mixed-

316 effects models using average leaf-out / flowering dates or LOS / FLS as response variables,

317 preseason temperature as explanatory variable, and site as a random effect to control for the use

318 of different sites in the model.

319 To test for the relative effects of preseason temperature on (i) inter-individual variation

320 in leaf-out/flowering date (LOS / FLS) and (ii) inter-individual variation in forcing requirements

321 until leaf-out/flowering (LOS-DD / FLS-DD) we applied hierarchical Bayesian models. To test

322 for the effects of winter chilling and day-length on phenological synchrony, we applied

323 hierarchical Bayesian models including both winter chilling until leaf-out and day length at the

324 date when the average forcing requirements until leaf-out or flowering were fulfilled as predictor

325 variables. The use of a Bayesian framework allowed us to fit slope parameters across traits

326 simultaneously without concerns of multiple testing or $P$-value correction. All models included

327 random effects for (i) species (to address within-species rather than between species phenological

328 synchrony) and (ii) pixels (to address within-population rather than between-population

329 phenological synchrony). To allow for direct effect size comparisons, all continuous variables 
330 were standardized by subtracting their mean and dividing by 2 SD before analysis (31). The

331 resulting posterior distributions are a direct statement of the probability of our hypothesized

332 relationships. Effective posterior means $\pm 95 \%$ confidence intervals are shown in Fig. 2.

333 To parameterize our models, we used the JAGS implementation (32) of Markov chain

334 Monte Carlo methods in the R package R2JAGS (33). We ran three parallel MCMC chains for

335200,000 iterations with a 50,000-iteration burn-in and evaluated model convergence with the

336 Gelman and Rubin (34) statistic. Noninformative priors were specified for all parameter

337 distributions, including normal priors for $\alpha$ and $\beta$ coefficients (fixed effects; mean =0; variance =

338 1,000), and uniform priors between 0 and 100 for the variance of the random intercept effects,

339 based on de Villemereuil and colleagues (35). All statistical analyses relied on R 3.2.2 (36).

341 Analysis of leaf-out synchrony (LOS) using common garden data from 2013-2018

342 Between 2013 and 2018 we observed the leaf-out dates of 209 individuals in 59 temperate woody

343 species (minimally 3 individuals per species) in the Munich Botanical garden (see Supplementary

344 Materials Table 1 for a list of species). An individual was scored as having leafed out when at

345 least three branches had unfolded leaves pushed out all the way to the petiole (37). To test

346 whether the trends observed in the PEP analysis are consistent with our common garden data, the

347 same parameters (LOS, LOS-DD, preseason temperature, winter chilling, and photoperiod) were

348 calculated as described above (Analysis of leaf-out and flowering synchrony (LOS and FLS)

349 using the PEP database). We then applied hierarchical Bayesian models including species

350 random effects (see paragraph above) to test for the effects of preseason temperature, winter

351 chilling, and day-length on LOS and LOS-DD. 


\section{$354 \quad$ Twig cutting experiments and phenological scoring}

355 To study the extent of intraspecific variation in leaf-out strategy (within-species variation in

356 photoperiod, chilling, and forcing requirements) and its implications under climate warming, we

357 conducted twig-cutting experiments on mature Fagus sylvatica individuals grown in the vicinity

358 of Munich. Experiments have demonstrated that twig cuttings precisely mirror the phenological

359 behavior of their donor plants and therefore are adequate proxies for inferring phenological

360 responses of adult trees to climatic changes $(27,38)$. We used twigs approximately $50 \mathrm{~cm}$ in

361 length, and immediately after cutting, we disinfected the cut section with sodium hypochlorite

362 solution (200 ppm active chlorine), cut the twigs a second time, and then placed them in 0.51

363 glass bottles filled with 0.41 cool tap water enriched with the broad-spectrum antibiotics

364 gentamicin sulfate (40 $\mu \mathrm{g}^{-1}$; Sigma-Aldrich, Germany) $(11,27)$. We then transferred the cut

365 twigs to climate chambers and kept them under short $(8 \mathrm{~h})$, intermediate $(12 \mathrm{~h})$, or long day (16

366 h) conditions (see Experiment 1 below), or natural day length (Experiment 2 below).

367 Temperatures in the climate chambers were held at $12^{\circ} \mathrm{C}$ during the night and $20^{\circ} \mathrm{C}$ during

368 the day, with an average daily temperature of $16^{\circ} \mathrm{C}$ to simulate forcing temperatures. Illuminance

369 in the chambers was about $8 \mathrm{klux}\left(\sim 100 \mu \mathrm{mol} \mathrm{s}^{-1} \mathrm{~m}^{-2}\right)$. Relative air humidity was held between

$37040 \%$ and $60 \%$. To account for within-individual variation, we used 10 replicate twigs per

371 individual treatment and monitored bud development every second day. For each individual and

372 treatment, we then calculated the mean leaf-out date out of the first eight twigs that leafed out. A

373 twig was scored as having leafed out when three buds had unfolded leaves pushed out all the way

374 to the petiole (37). Forcing requirements until leaf-out were calculated as the sum of degree-days

375 [outside of and in climate chambers] from 10 December ( $1^{\text {st }}$ collection date) until leaf-out using 
$3765^{\circ} \mathrm{C}$ as base temperature (e.g., ref. 27). Chilling hours were calculated as the sum of hours from 1

377 November until leaf-out with an average temperature between $0^{\circ} \mathrm{C}$ and $5^{\circ} \mathrm{C}$.

378

379 Experiment 1: Differences in photoperiod sensitivity among Fagus sylvatica individuals

380 In winter 2014/2015, twigs of 11 individuals (10 replicate twigs per individual and treatment) of

381 Fagus sylvatica were collected at three dates during winter (22 Dec 2014, 6 Feb 2015, and 21

382 Mar 2015) and brought into climate chambers. Additionally, we collected twigs from one

383 individual each of Fagus crenata and Quercus robur. Temperatures in the chambers ranged from

$38412^{\circ} \mathrm{C}$ during night to $20^{\circ} \mathrm{C}$ during day, with an average daily temperature of $16^{\circ} \mathrm{C}$. Day length in

385 the chambers was set to $8 \mathrm{~h}, 12 \mathrm{~h}$, or $16 \mathrm{~h}$.

386 Individual photoperiod sensitivity was defined as the slope of the function between day-

387 length treatment and accumulated degree days $\left(>5^{\circ} \mathrm{C}\right)$ until leaf-out (twigs were collected on 21

388 March; see Fig. 3b). The steeper the slope, the stronger the effect of photoperiod on the amount

389 of warming required for leaf-out. A flat slope indicates that photoperiod has no effect on the

390 timing of leaf-out.

$391 \quad$ Individual chilling sensitivity was defined as the slope of the function between chilling

392 treatment (collection date) and accumulated degree days $\left(>5^{\circ} \mathrm{C}\right)$ until leaf-out when twigs were

393 kept under constant 16-h day length (see Fig. 3c). The steeper the slope, the stronger the effect of

394 chilling on the amount of warming required for leaf-out.

395 Individual forcing requirement was defined as the accumulated degree days $\left(>5^{\circ} \mathrm{C}\right)$ until

396 leaf-out under long chilling (21 March collection) and constant 16-h day length (see Fig. 3a).

397 Under such conditions, chilling requirements and photoperiod requirements should be largely

398 met, and thus the remaining variation in leaf-out dates should be largely attributable to

399 differences in forcing (warming) requirements. 
401 In winter 2015/2016, twigs from the same 11 individuals were harvested every two weeks (from

40210 December until $21 \mathrm{March}$ ) and kept under the same temperature conditions applied in

403 experiment $1\left(12^{\circ} \mathrm{C}\right.$ during night to $20^{\circ} \mathrm{C}$ during day), with natural day length. This allowed us to

404 test if those individuals with no/little photoperiod sensitivity would advance their leaf-out more

405 under short winter conditions than photoperiod-sensitive individuals, and to determine the

406 relative effect of individual variation in photoperiod requirements, chilling requirements and

407 forcing requirements on leaf-out variation under different winter/spring conditions (Fig. 4).

408 Within-species leaf-out synchrony (LOS) was calculated as the standard deviation of individual

409 leaf-out dates. To analyze which leaf-out cues (photoperiod, chilling, and forcing requirements)

410 best explain leaf-out variation among individuals, we applied a multivariate linear model,

411 including individual forcing, photoperiod, and chilling requirements (as inferred from experiment

412 1) as explanatory variables. To express the total variation in leaf-out dates that can be attributed

413 to each trait, we used ANOVA sums of squares (see Fig. 4d).

414 To infer which percentage of the variation in leaf-out dates is due to treatment effects,

415 between-individual variation, or within-individual variation, we calculated variance components

416 by applying a random-effects-only model including treatments and individuals as random effects

417 (individuals nested within treatments). Results show that of the total leaf-out variation among

418 twigs, $52 \%$ can be explained by between-individual variation, $33 \%$ by treatments, and only $15 \%$

419 by within-individual variation (Supplementary Fig. S9).

420

421

422

423 


\section{References}

425 1. Anker Ims R (1990) The ecology and evolution of reproductive synchrony. Trends Ecol Evol

$426 \quad 5: 135-140$.

427 2. Fitter AH, Fitter RS (2002) Rapid changes in flowering time in British plants. Science

$428 \quad 296: 1689-1691$.

429 3. Sherry RA, Zhou X, Gu S, Arnone JA, Schimel DS, et al. (2007) Divergence of reproductive

430 phenology under climate warming. Proc Natl Acad Sci USA 104:198-202.

431 4. Thackeray SJ, Henrys PA, Hemming D, Bell JR, Botham MS, Burth S, et al. (2016)

432 Phenological sensitivity to climate across taxa and trophic levels Nature 535:241-245.

433 5. Menzel A, Fabian P (1999) Growing season extended in Europe. Nature 397:659.

434 6. Chuine I, Beaubien E (2001) Phenology is a major determinant of temperate tree range. Ecol

$435 \quad$ Lett 4:500-510.

436 7. Elzinga JA, Atlan A, Biere A, et al. (2007) Time after time: flowering phenology and biotic

437 interactions. Trends Ecol Evol 22:432-439.

438 8. Chuine I (2010) Why does phenology drive species distribution? Phil Trans $R$ Soc $B$

$439 \quad 365: 3149-3160$.

440 9. Zohner CM, Benito, BM, Fridley JD, Svenning J-C, Renner SS (2017) Spring predictability

441 explains different leaf-out strategies in the woody floras of North America, Europe, and

$442 \quad$ East Asia. Ecol Lett 20:452-460.

443 10. Laube J, et al. (2014) Chilling outweighs photoperiod in preventing precocious spring

444 development. Glob Change Biol 20:170-182. 
445 11. Zohner CM, Benito BM, Svenning J-C, Renner SS (2016) Day length unlikely to constrain

446 climate-driven shifts in leaf-out times of northern woody plants. Nat Clim Change

$447 \quad 6: 1120-1123$.

448 12. Hart SP, Schreiber SJ, Levine JM (2016) How variation between individuals affects species $449 \quad$ coexistence. Ecol Lett 19:825-38.

450 13. Augspurger CK (2013) Reconstructing patterns of temperature, phenology, and frost damage 451 over 124 years: spring damage risk is increasing. Ecology 94:41-50.

452 14. Wang C, Cao R, Chen J, Rao Y, Tang Y (2015) Temperature sensitivity of spring vegetation 453 phenology correlates to within-spring warming speed over the Northern Hemisphere. $454 \quad$ Ecol Indic 50:62-68.

455 15. Wang C, Tang Y, Chen J (2016) Plant phenological synchrony increases under rapid within$456 \quad$ spring warming. Sci Rep 6:25460.

457 16. Augspurger CK (1981) Reproductive synchrony of a tropical shrub: Experimental studies on 458 effects of pollinators and seed predators in Hybanthus prunifolius (Violaceae). Ecology $459 \quad 62: 775-788$.

460 17. Kollas C, Körner C, Randin CF (2014) Spring frost and growing season length co-control the 461 cold range limits of broad-leaved trees. J Biogeogr 41:773-783.

462 18. Vitasse Y, Lenz A, Körner C (2014) The interaction between freezing tolerance and 463 phenology in temperate deciduous trees. Front Plant Sci 5:541.

464 19. Keenan TF, et al. (2014) Net carbon uptake has increased through warming-induced changes 465 in temperate forest phenology. Nat Clim Change 4:598-604.

466 20. Körner C, Basler D (2010) Phenology under global warming. Science 327:1461-1462.

467 21. Antonovics J, Bradshaw AD (1970) Evolution in closely adjacent plant populations Part 8. 
469

470

471

472

473

474

475

476

477

478

479

480

481

482

483

484

485

486

487

488

489

490

491

22. Kirkpatrick M (2000) Reinforcement and divergence under assortative mating. Proc Royal Soc B 267:1649-1655.

23. Weis AE, Kossler TM (2004) Genetic variation in flowering time induces phenological assortative mating: quantitative genetic methods applied to Brassica rapa. Am J Bot $91: 825-836$.

24. Renner SS, Zohner CM (2018) Climate change and phenological mismatch in trophic interactions among plants, insects, and vertebrates. Annu Rev Ecol Evol Syst in press.

25. Jump AS, Penuelas J (2005) Running to stand still: adaptation and the response of plants to rapid climate change. Ecology Letters 8: 1010-1020.

26. Vitasse Y, Signarbieux C, Fu YH (2018) Global warming leads to more uniform spring phenology across elevations. Proc Natl Acad Sci USA. doi/10.1073/pnas.1717342115

27. Zohner CM, Renner SS (2015) Perception of photoperiod in individual buds of mature trees regulates leaf-out. New Phytol 208:1023-1030.

28. Beer C, et al. (2014) Harmonized European long-term climate data for assessing the effect of changing temporal variability on land-atmosphere CO2 fluxes. J Clim 27:4815-4834.

29. Fu YH, et al. (2015) Declining global warming effects on the phenology of spring leaf unfolding. Nature 526:104-107.

30. Forsythe WCR, Rykiel EJ, Stahl RS, Wu H, Schoolfield RM (1995) A model comparison for daylength as a function of latitude and day of year. Ecol Modell 80:87-95.

31. Gelman A, Hill J (2007) Data analysis using regression and multilevel/hierarchical models. Cambridge, UK: Cambridge University Press.

32. Plummer M (2003) JAGS: a program for analysis of Bayesian graphical models using Gibbs sampling. In: Hornik K, Leisch F, Zeileis A, eds. Proceedings of the 3rd International 

Zeileis.

494 33. Su Y-S, Yajima M (2014) R2jags: a package for running JAGS from R. R package version 0.04-03. [WWW document] URL http://CRAN.R-project.org/package=R2jags

34. Gelman A, Rubin DB (1992) Inference from iterative simulation using multiple sequences. Statistical Science 7:457-472.

498 35. de Villemereuil P, Wells JA, Edwards RD, Blomberg SP (2012) Bayesian models for comparative analysis integrating phylogenetic uncertainty. BMC Evolutionary Biology 12:102.

36. R Core Team. 2018. R: a language and environment for statistical computing, version 3.4.1. Vienna, Austria: R Foundation for Statistical Computing. URL http:/www.Rproject.org/

504 37. IPG. Phenological observation guide of the International Phenological Gardens. International Phenological Gardens of Europe, Berlin, Germany. [WWW document] URL https://www.agrar.hu-berlin.de/en/institut-en/departments/dntw-en/agrarmeten/phaenologie/ipg/IPG_ObsGuide.pdf [accessed 1 August 2017]. 


\section{Acknowledgements}

516 We thank D. März and V. Sebald for help with the experiments and R. Ricklefs for comments on

517 the manuscript. This work benefitted from the sharing of expertise within the DFG priority

518 program SPP 1991.

519

520

521 Statement of authorship: CMZ designed the study, performed the experiments and analyzed the

522 data. LM contributed to the analyses. CMZ and SSR wrote the manuscript.

523

524

525

526

527

528

529

530

531

532

533

534

535

536

537

538 

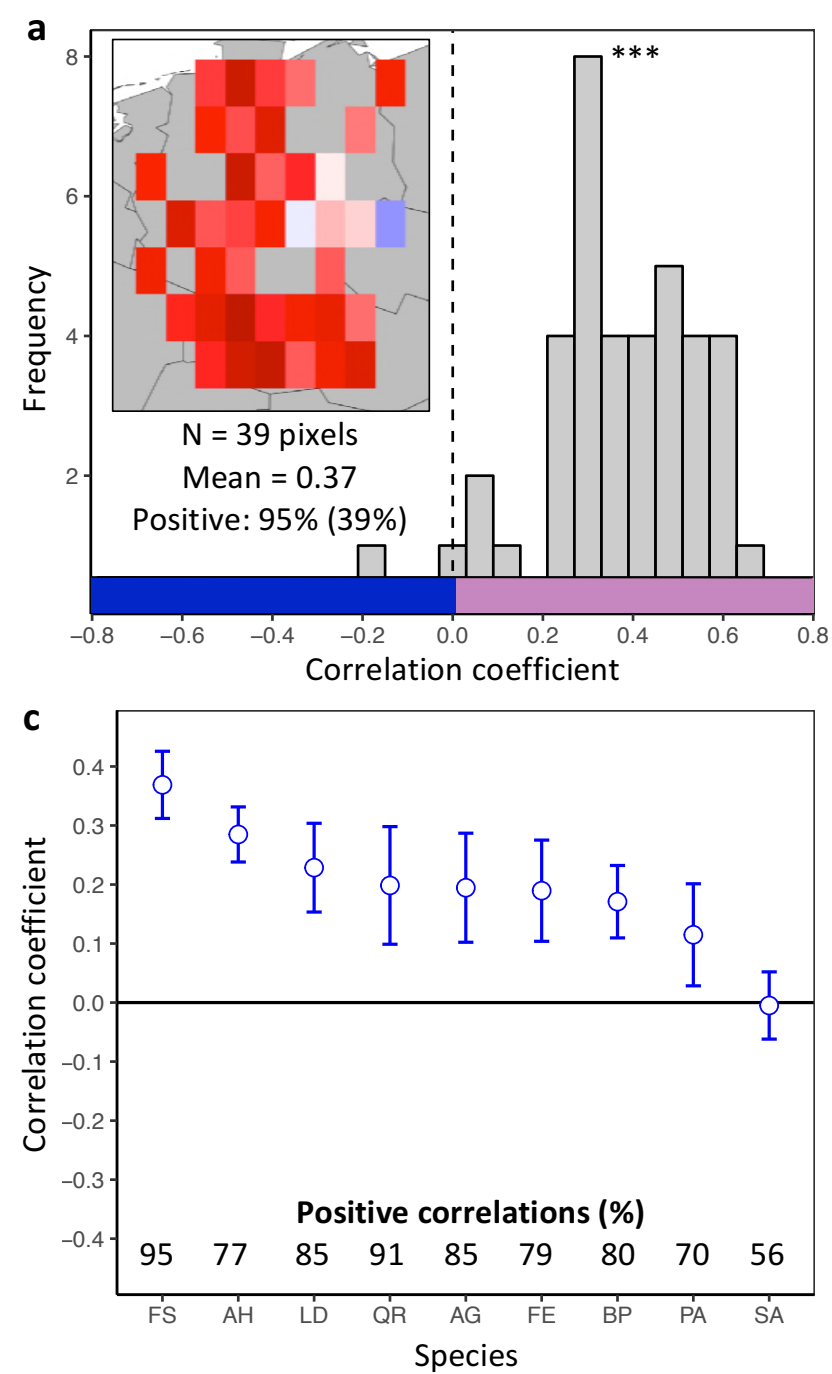

540

541

542

543

544

545

546

547

548

549

550

551

552

553

554

555

556

557

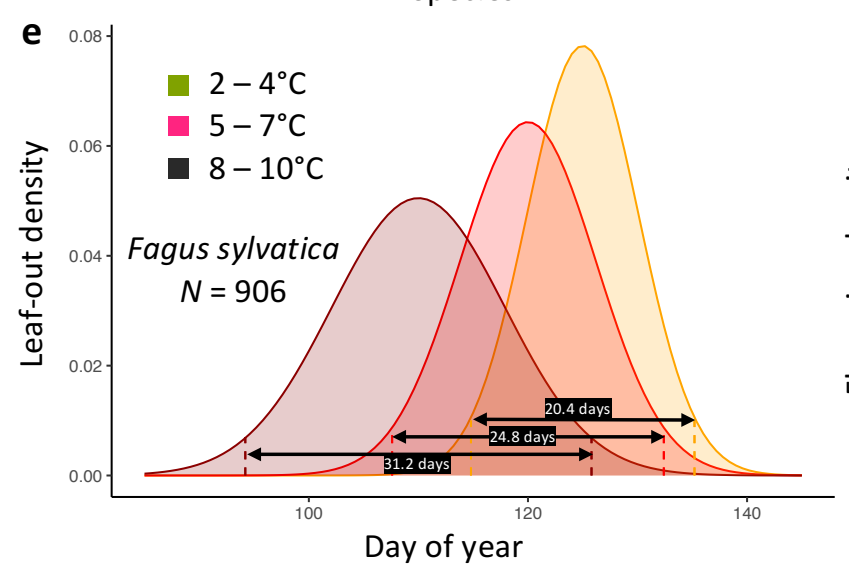

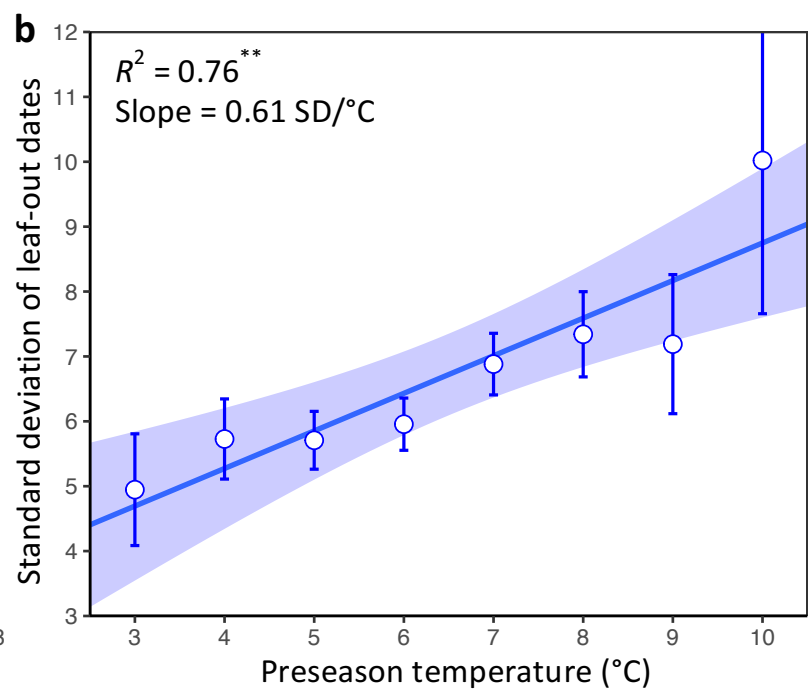

d
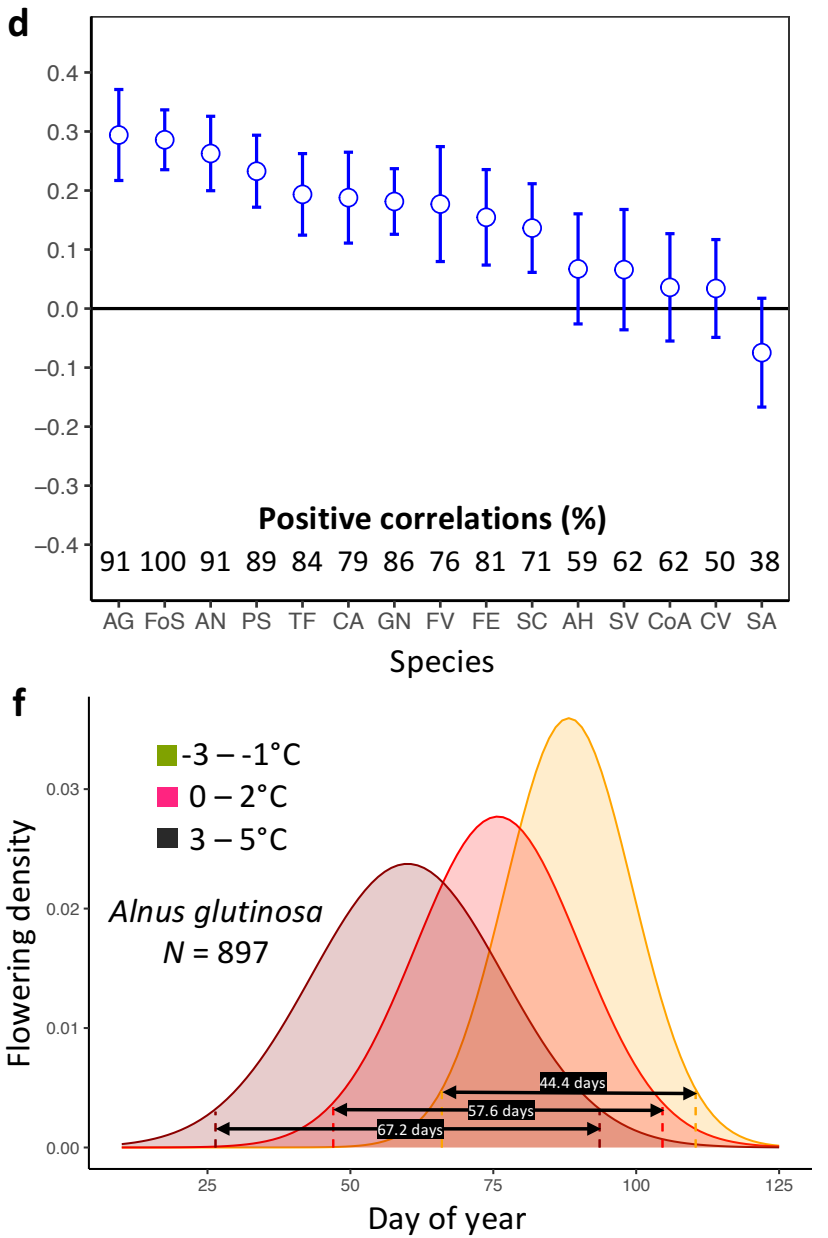
Figure 1 | Loss of inter-individual synchrony in leaf-out and flowering with increasing of inter-individual leaf-out times and spring temperature for Fagus sylvatica at 39 pixels $\left(1^{\circ} \times 1^{\circ}\right.$ areas). . Mean $=$ Mean correlation coefficients across all sites $(N)$, Positive $=$ percentage of positive correlations and the percentage of statistically significant positive correlations (in parentheses). Inset shows a heat map of the correlations at the 39 pixels. b, Effect of preseason temperature on the standard deviation of inter-individual leaf-out times (mean $\pm \mathrm{SEM}$ ) in $F$. sylvatica averaged across all years and sites. c, d, Mean Pearson correlation coefficients $( \pm 95 \%$ confidence intervals) for the effect of spring temperature on the standard deviation of interindividual leaf-out (c) or flowering times (d). Positive correlations $=$ percentage of the total number of positive correlations. See Figs. S1b and S2b for number of sites $\left(1^{\circ} \times 1^{\circ}\right.$ areas $)$ in which the relationship was analyzed. e, f, Distributions of inter-individual (e) leaf-out dates in $F$. sylvatica and (f) flowering dates in Alnus glutinosa under different spring temperatures. $N=$ Number of available year x pixel $\left(1^{\circ} \times 1^{\circ}\right.$ areas) combinations. To model the distributions (means and standard deviations), mixed-effects models were applied including site (pixel) as a random effect. See Figs. S3 and S4 for distributions of all 20 analyzed species. AG, Alnus glutinosa; AH, Aesculus hippocastanum; AN, Anemone nemorosa; BP, Betula pendula; CA, Corylus avellana; CoA; Colchicum autumnale; CV, Calluna vulgaris; FE, Fraxinus excelsior; FoS, Forsythia suspensa; FS, Fagus sylvatica; FV, Fragaria vesca; GN, Galanthus nivalis; LD, Larix decidua; PA, Picea abies; PS, Prunus spinosa; QR, Quercus robur; SA, Sorbus aucuparia; SC, Salix

579 caprea; SV, Syringa vulgaris; TF, Tussilago farfara.

580

581

582

583

584

585

586 
602

\section{a}

a Preseason temperature

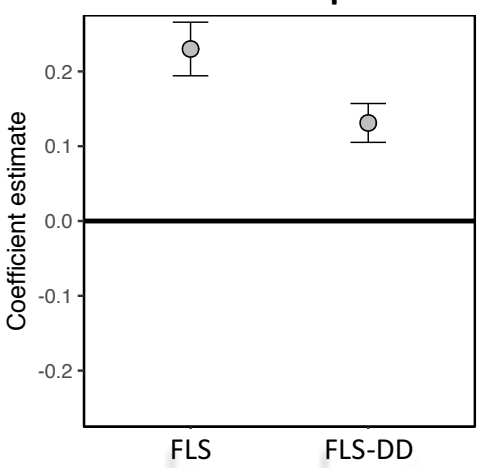

b

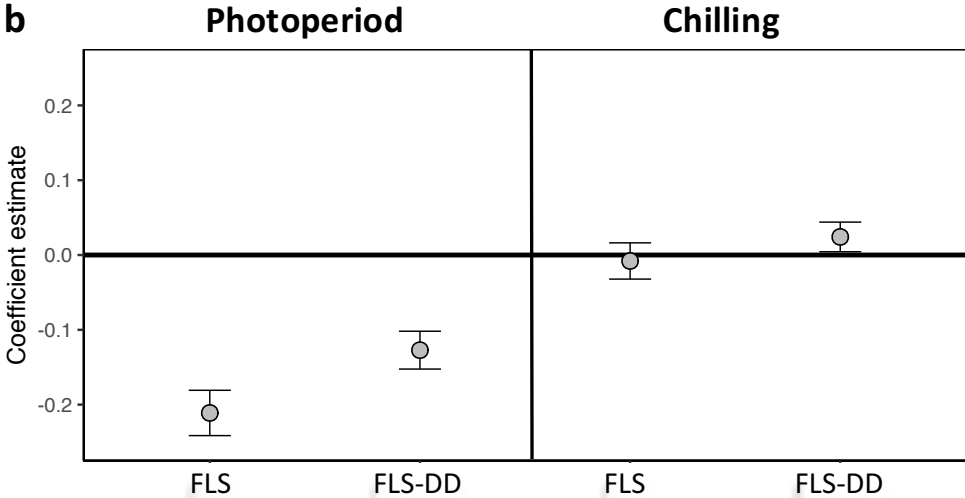

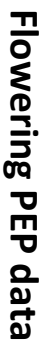

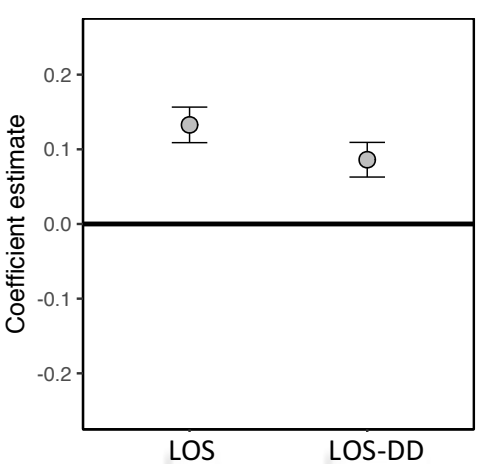

603

604

605

606

607

608

609

610

611

612

613

614

615

616

617

618

619
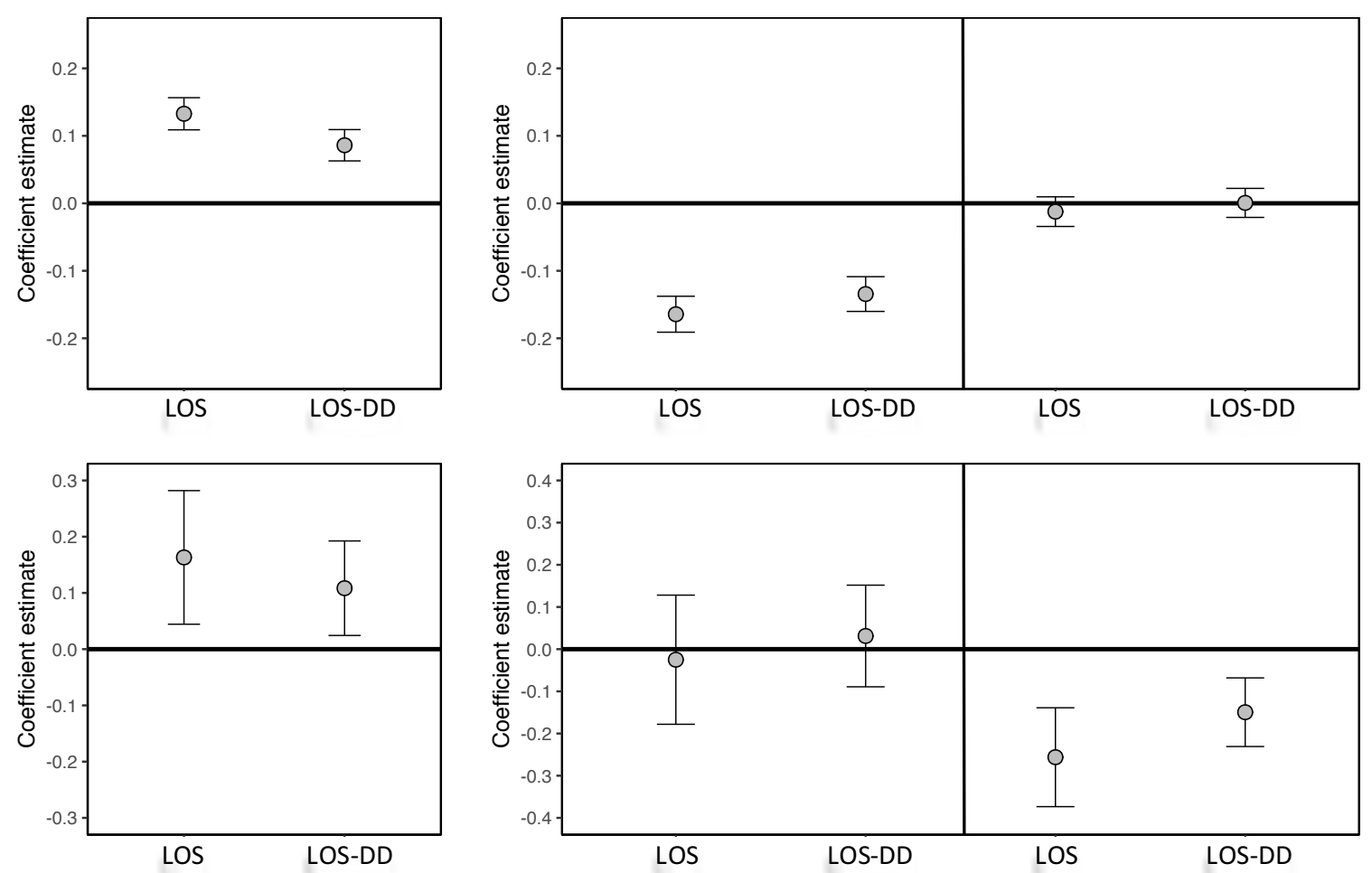

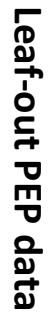

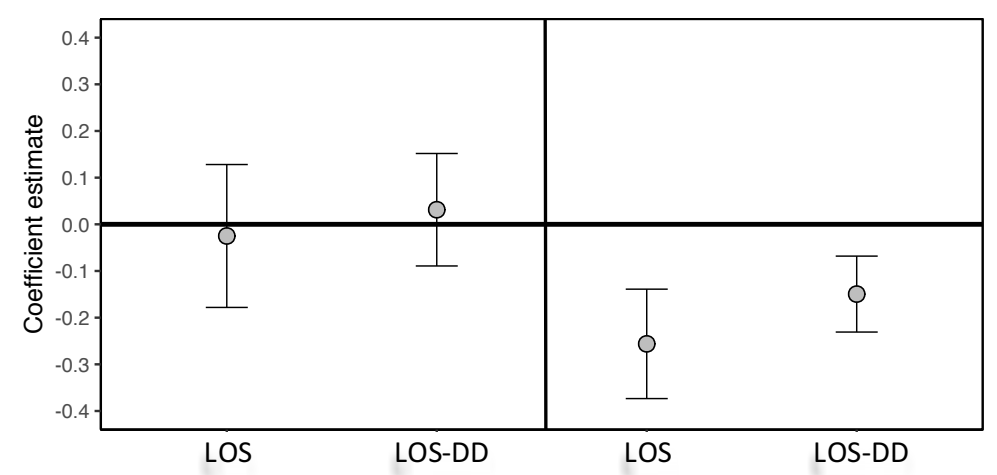

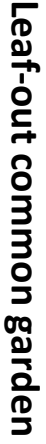

Figure 2 | The environmental drivers of inter-individual phenological synchrony as inferred from (i) flowering times (upper panels) and (ii) leaf-out times (middle panels) using the PEP data, and (iii) common garden observations on leaf-out times. a, Coefficient estimates (effective posterior means $\pm 95 \%$ credible intervals) for the effect of preseason temperature (mean temperature 2 months before a species' mean leaf-out/flowering date) on inter-individual phenological synchrony measured either as the standard deviation in leaf-out/flowering dates (LOS / FLS; left) or the standard deviation in degree-day (DD) requirements among individuals (LOS-DD / FLS-DD; right). b, Coefficient estimates for the effects of photoperiod and winter chilling on inter-individual leaf-out synchrony. Hierarchical Bayesian linear models were applied using information on 13 (upper), 9 (middle), and 59 species (lower panels). To account for within-species rather than among-species synchrony, all models include species random effects. The models using the PEP data (upper and middle panels) additionally include site random effects ( $1^{\circ}$ pixels) to address within-population phenological synchrony. All variables were standardized to allow for direct effect size comparisons.

620 

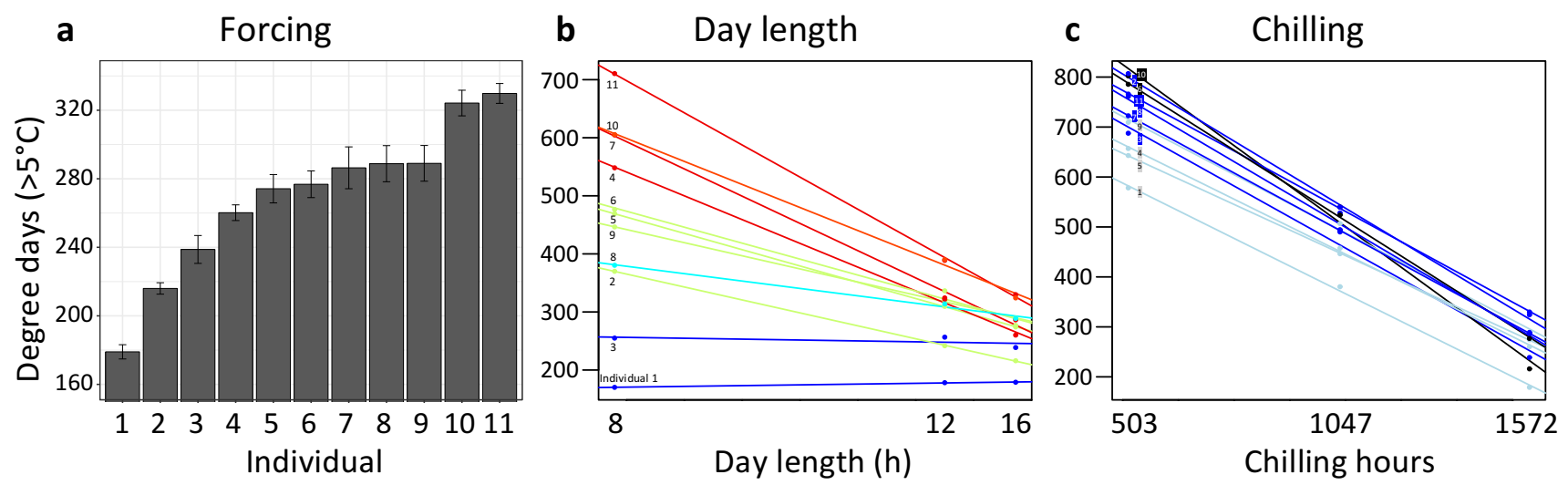

624

625

Figure 3 | Individual differences in the forcing (a), day-length (b), and chilling (c)

626 requirements among 11 beech trees $(\boldsymbol{F}$. sylvatica; Experiment 1$)$. a, Mean $( \pm \mathrm{SEM})$ forcing

627 requirements (accumulative degree days $>5^{\circ} \mathrm{C}$ ) until budburst under long chilling and constant

628 16-h day length. b, Degree days until budburst at 8-h, 12-h, and 16-h day length (collection date:

629 21 March 2015). Colours according to slope (red: steep slope; blue: no slope). c, Degree days until budburst under short, intermediate, and long chilling (collection dates: 22 Dec 2014, 6 Feb

631 2015, 21 March 2015) and 16-h day length. Colours according to slope (dark blue: steep slope;

632 light blue: no slope).

633

634

635

636

637

638

639

640

641

642

643

644

645

646

647

648

649

650

651 
652

653

654

655

656

657

658

659

660

661

662

663

664

665

666

667

668

669

670

671
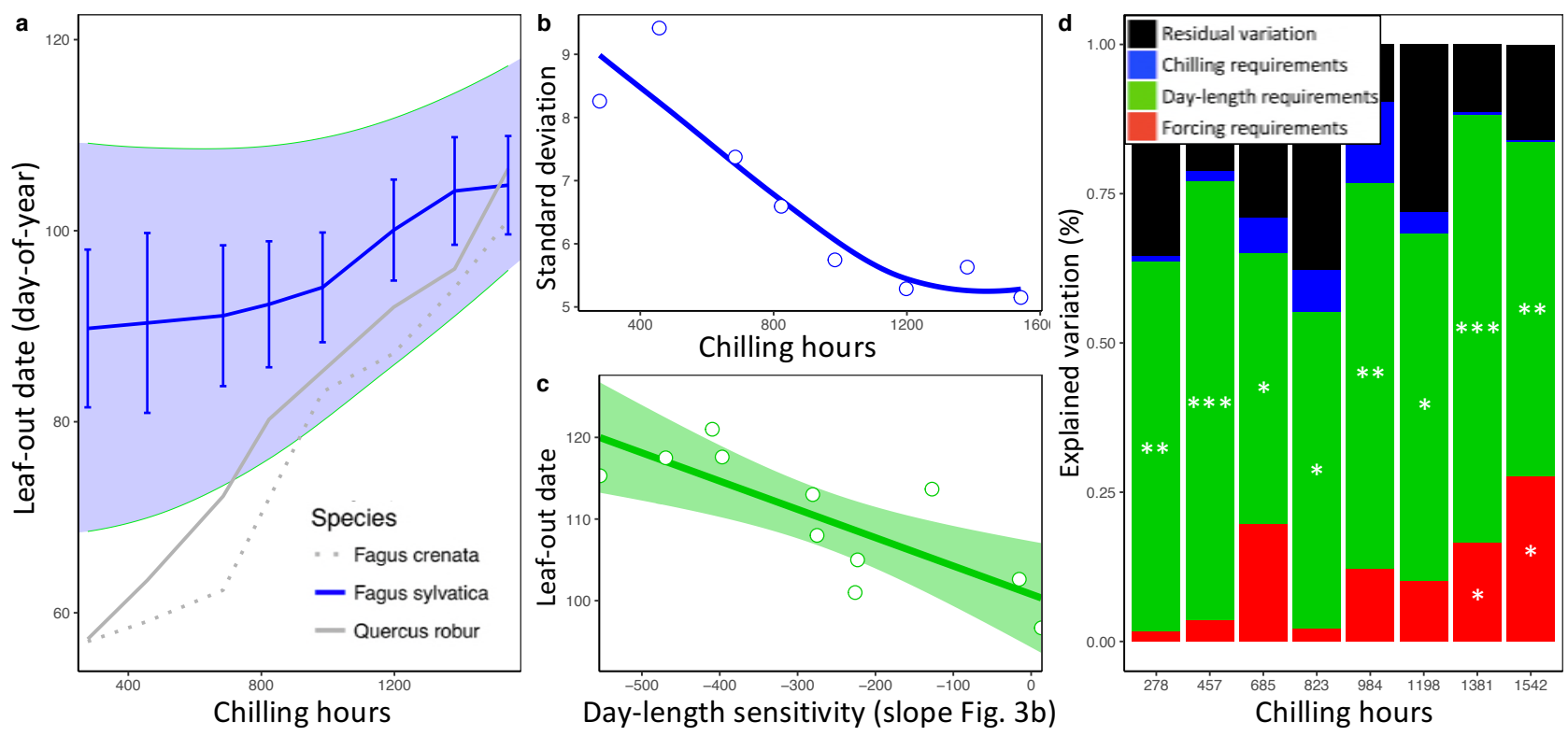

Figure 4 | Loss of phenological synchrony with climate warming is explained by contrasting day-length sensitivities in Fagus sylvatica. a, b, Experiment 2. a, Leaf-out dates of Fagus sylvatica (blue), Fagus crenata (dotted grey), and Quercus robur (grey) under varying winter lengths (chilling hours $=$ sum of hours from 1 November until leaf-out with an average temperature between $0^{\circ} \mathrm{C}$ and $5^{\circ} \mathrm{C}$ ). Bars show the standard deviation of average leaf-out dates among $11 \mathrm{~F}$. sylvatica individuals. The shaded area shows the difference between the leaf-out date of the first flushing twig of the first individual and the last twig of the last individual to leafout, using a LOESS smoothing function. For F. crenata and Q. robur, we investigated one individual each and therefore do not report inter-individual variation. $\mathbf{b}$, Standard deviation of leaf-out dates among $11 \mathrm{~F}$. sylvatica individuals at different winter lengths (chilling levels) and natural day length. c, The effect of individual day-length sensitivity on the timing of leaf unfolding when twigs were collected on 10 December 2015. Note the reversed x-axis scale, i.e., smaller values indicate higher day-length sensitivity. d, Variables explaining the sequence of leaf-out dates of $11 \mathrm{~F}$. sylvatica individuals at eight different chilling levels. The percentage of leaf-out variation (derived from the ANOVA sums of squares) that can be explained by individual forcing requirements (red), day-length requirements (green), chilling requirements (blue), and the remaining residuals, i.e., unexplained variation (black). ${ }^{*} P<0.05$; $* * P<0.01$; $* * * P<0.001$. 
bioRxiv preprint doi: https://doi.org/10.1101/391714; this version posted August 14,2018 . The copyright holder for this preprint (which was not certified by peer review) is the author/funder, who has granted bioRxiv a license to display the preprint in perpetuity. It is made available under aCC-BY 4.0 International license.

\section{Supplementary Material}




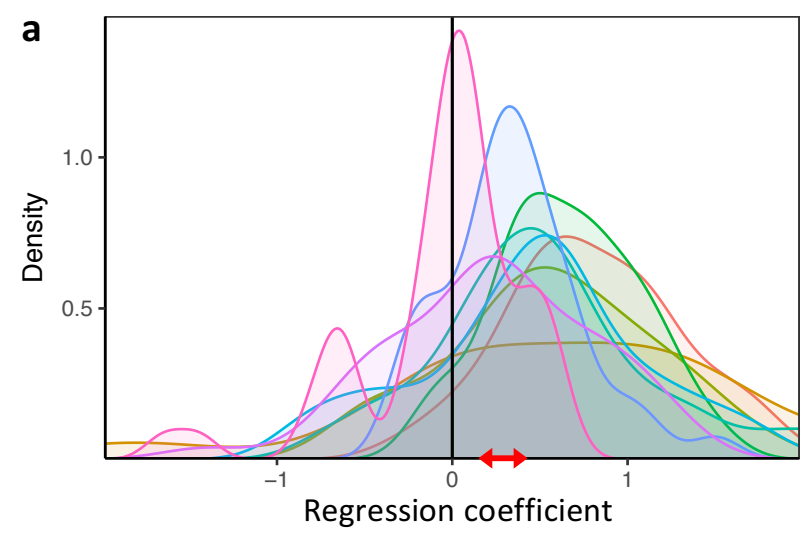

b Fagus sylvatica

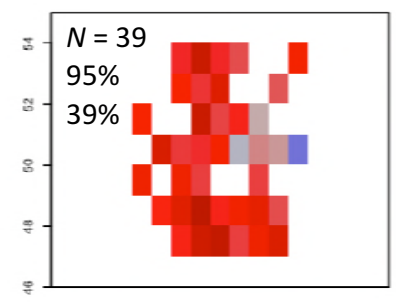

Aesculus hippocastanum
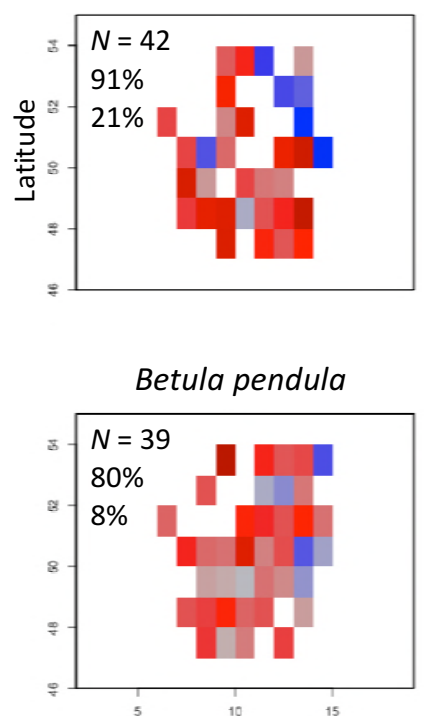

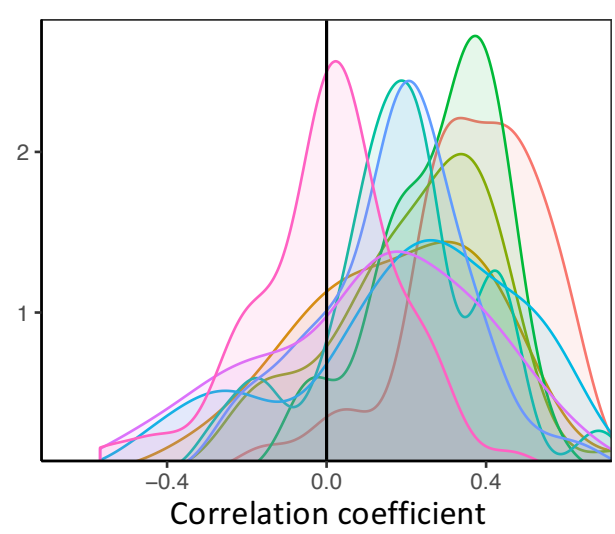

F. sylvatica

A. glutinosa

L. decidua

A. hippocast.

F. excelsior

Q. robur

B. pendula

P. abies

S. aucuparia

Correlation coefficient
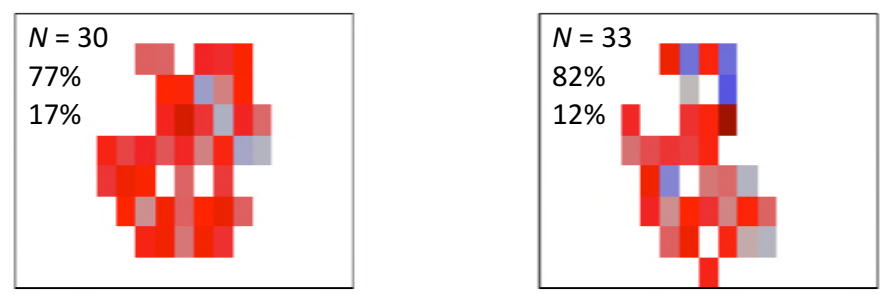

$-0.4$
Fraxinus excelsior

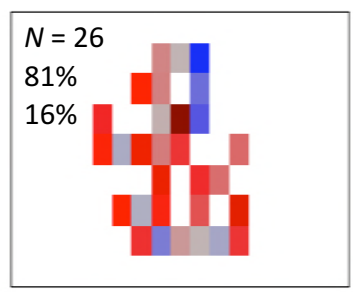

Quercus robur

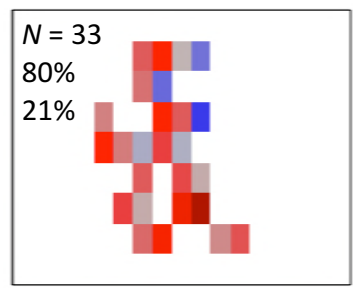

0.0

Sorbus aucuparia

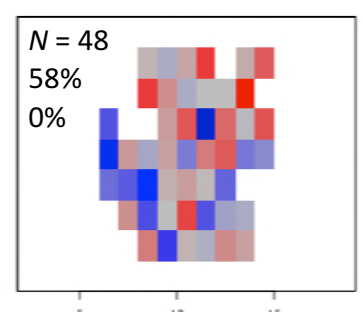

songitude

0.8

0.4

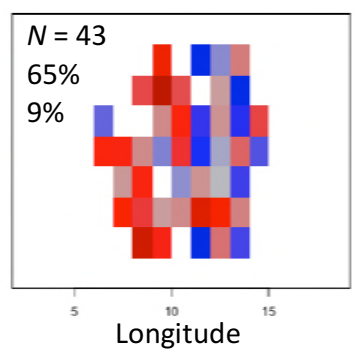

Figure S1 | Effects of preseason temperature on inter-individual leaf-out synchrony (LOS), using PEP data. a, Density plots of regression (left) and Pearson correlation coefficients (right) between LOS and preseason temperature for nine species. Regression coefficients show the change in LOS per each degree increase in preseason temperature. The red arrow indicates the range of regression coefficients obtained when simulating spring phenology with a degree-day model (see Extended Data Fig. 5). b, Maps showing the regression coefficients for the effect of temperature on LOS at each site (colour coding according to correlation coefficients). $N=$ Number of sites $\left(1^{\circ} \times 1^{\circ}\right.$ pixels) in which the relationship was analysed. Percentages are the proportion of positive correlations and significantly positive correlations, respectively. 

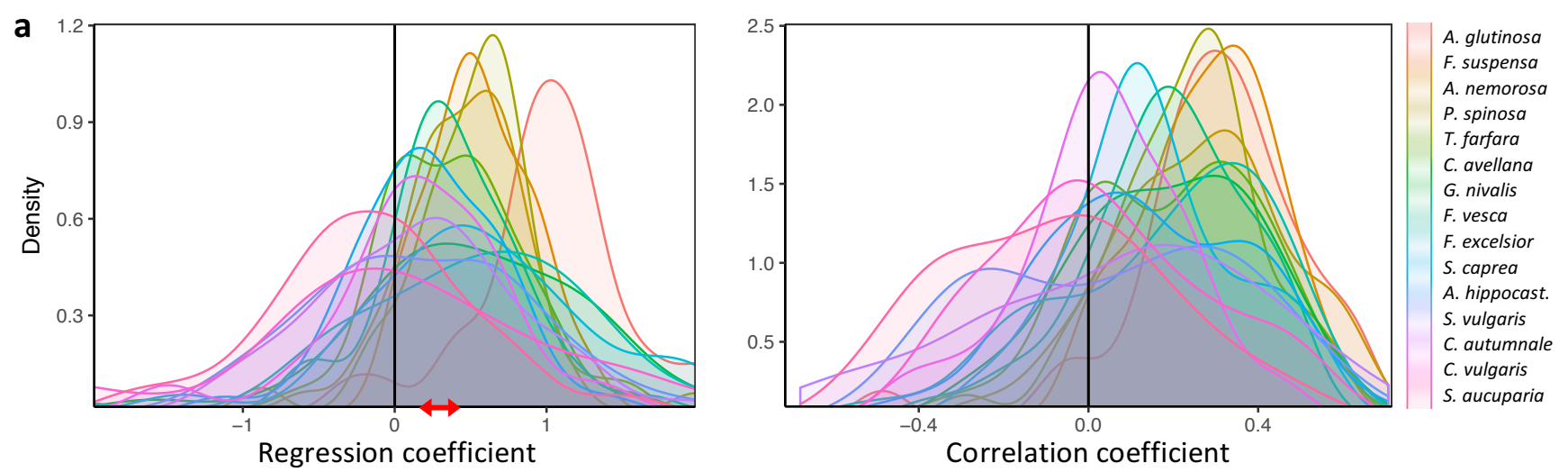

b

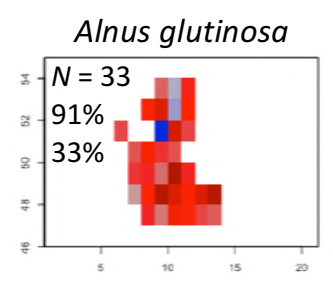

Tussilago farfara
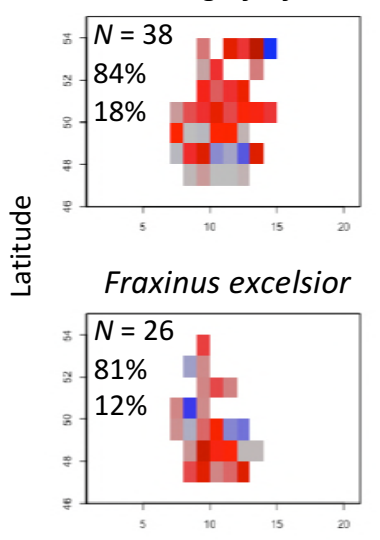

Colchicum autumnale

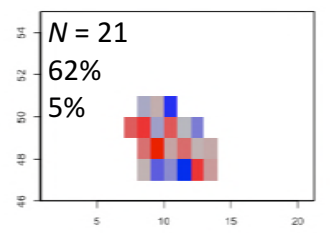

Forsythia suspensa

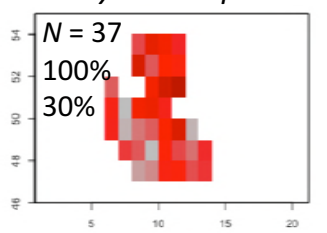

Corylus avellana

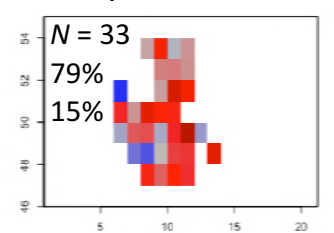

Salix caprea

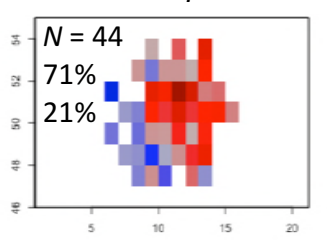

Calluna vulgaris

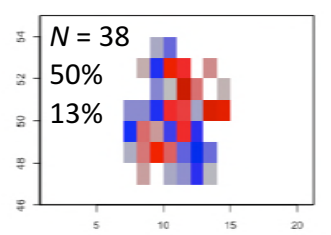

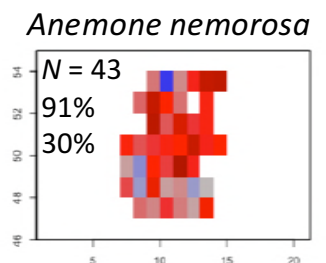

Galanthus nivalis

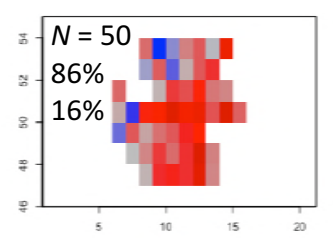

Aesculus hippocastanum

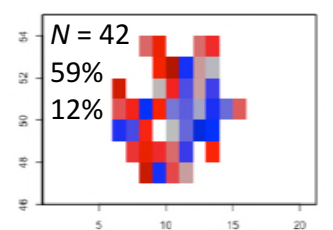

Sorbus aucuparia

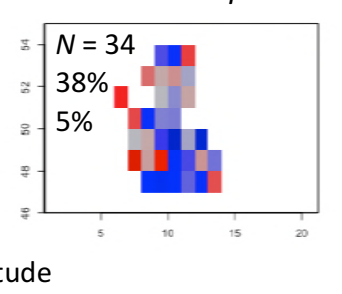

Prunus spinosa

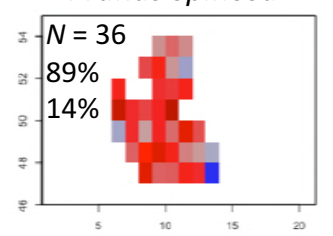

Fragaria vesca

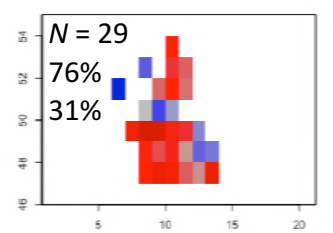

Syringa vulgaris

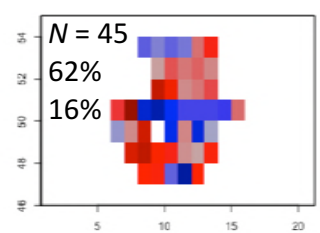

Correlation coefficient

$\begin{array}{lll}-0.75 & 0 & 0.75\end{array}$

Figure S2 | Effects of preseason temperature on inter-individual flowering synchrony (FLS), using PEP data. a, Density plots of regression (left) and Pearson correlation coefficients (right) between FLS and spring temperature for 15 species. Regression coefficients show the change in FLS per each degree increase in spring temperature. The red arrow indicates the range of regression coefficients obtained when simulating spring phenology with a degree-day model (see Extended Data Fig. 5). b, Maps showing the correlation coefficients for the effect of temperature on FLS at each site (colour coding according to correlation coefficients). $N=$ Number of sites $\left(1^{\circ} \times 1^{\circ}\right.$ areas $)$ in which the relationship was analysed. Percentages are the proportion of positive correlations and significantly positive correlations, respectively. 

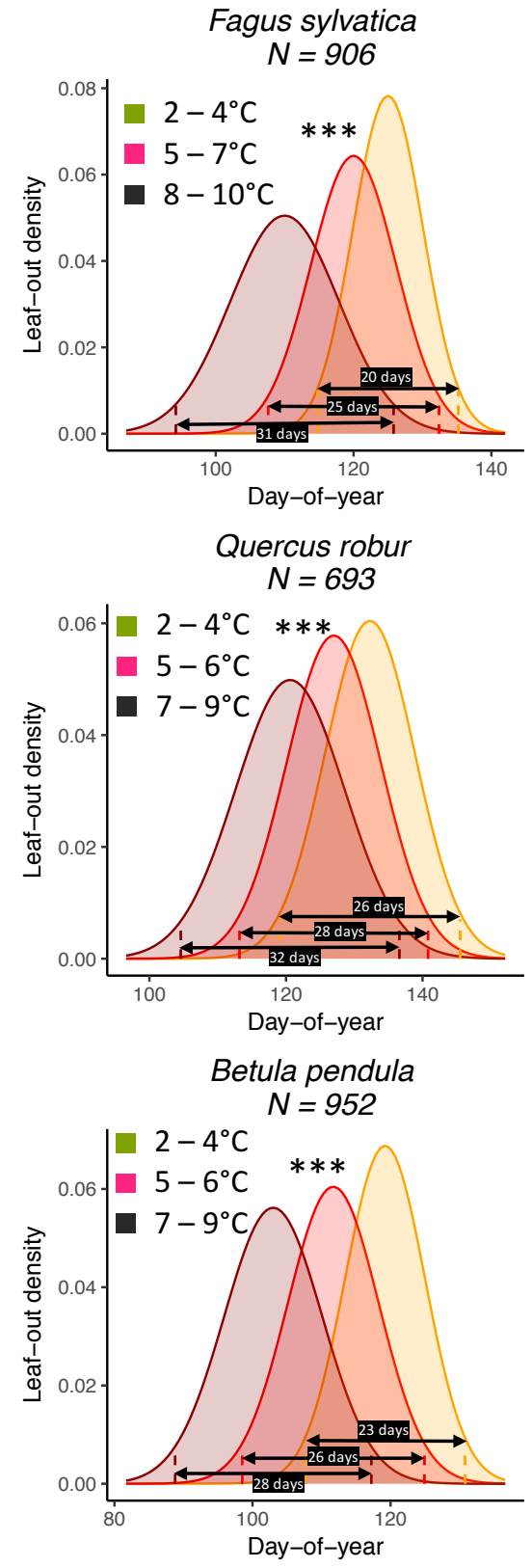
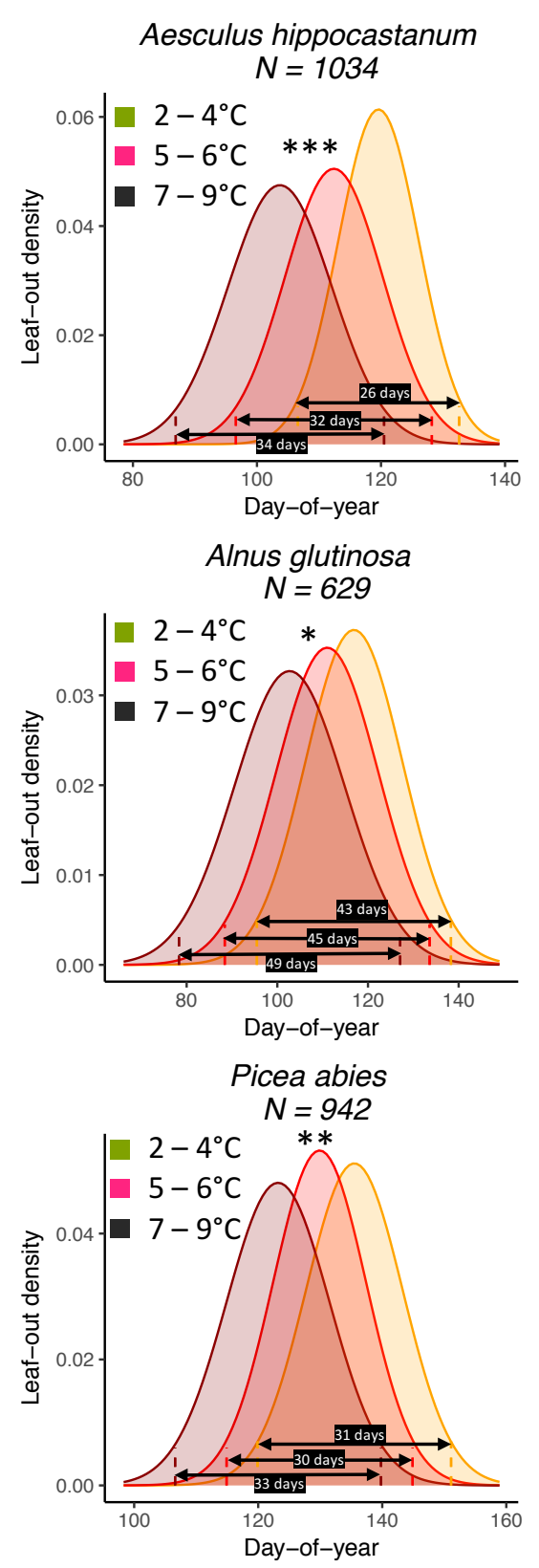
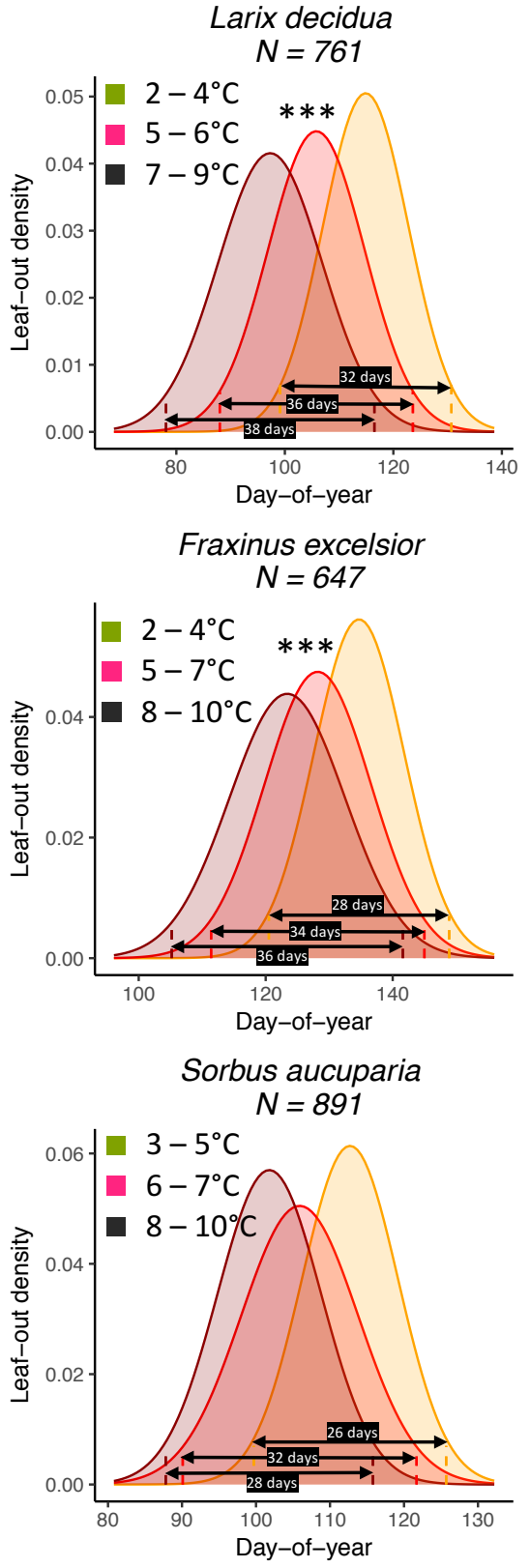

Figure S3 | The effect of preseason temperature on inter-individual (within-population) leaf-out distributions. $N=$ Number of available year $\mathrm{x}$ site $\left(1^{\circ} \mathrm{x} 1^{\circ}\right.$ areas $)$ combinations. To model the distributions (means and standard deviations), mixed-effects models were applied including site as a random effect. Stars indicate a significant positive effect of preseason temperature on $\operatorname{LOS}(* P<0.05 ; * * P<0.01 ; * * * P<0.001)$. Black arrows show the period in which $>95 \%$ of individuals leaf out (4 standard deviations), e.g., for Fagus sylvatica, in years with a cool preseason, $95 \%$ of individuals within a population leaf out within 20 days, whereas in years with a warm preseason this period is 31 days (55\% longer). 
bioRxiv preprint doi: https://doi.org/10.1101/391714; this version posted August 14,2018 . The copyright holder for this preprint (which was not certified by peer review) is the author/funder, who has granted bioRxiv a license to display the preprint in perpetuity. It is made available under aCC-BY 4.0 International license.

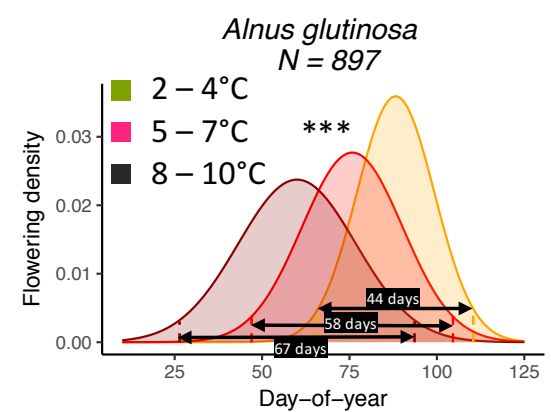

Prunus spinosa

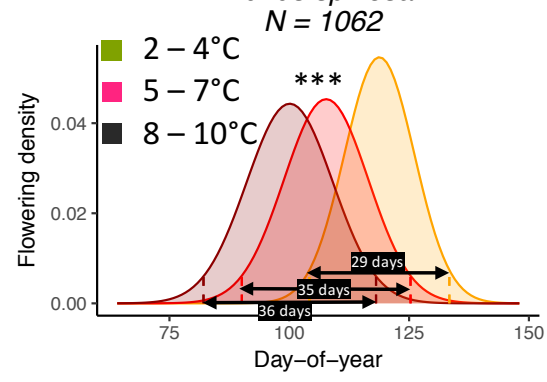

Galanthus nivalis

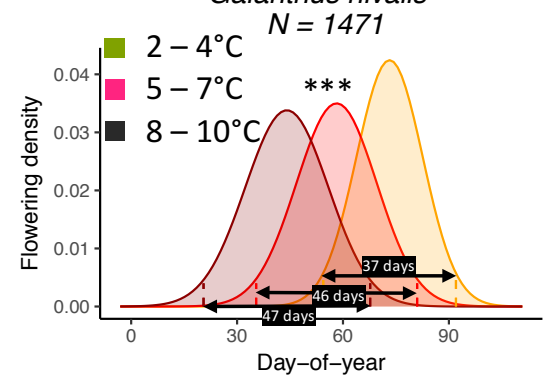

Salix caprea

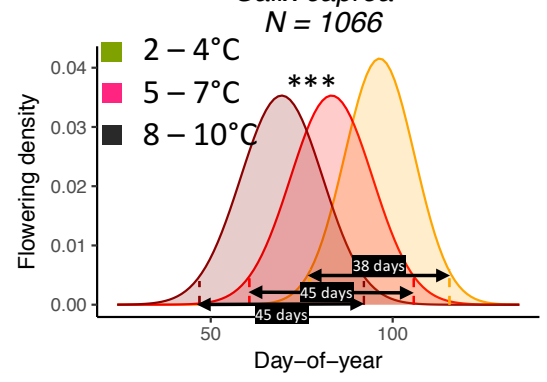

Colchicum autumnale $N=627$

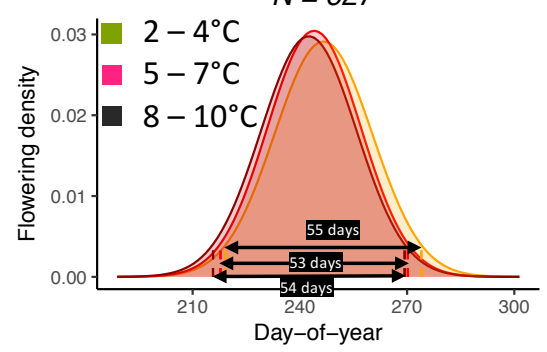

Forsythia ovata

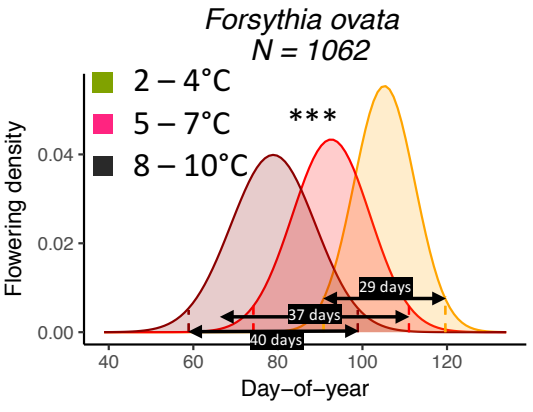

Tussilago farfara

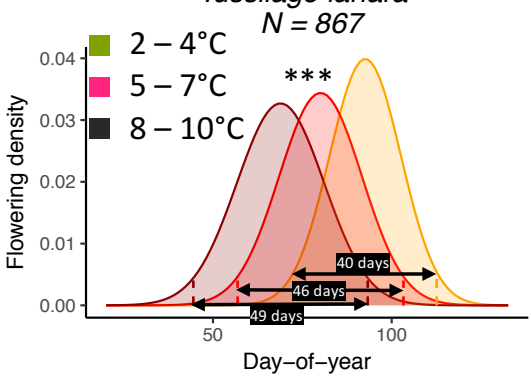

Fragaria vesca $N=815$

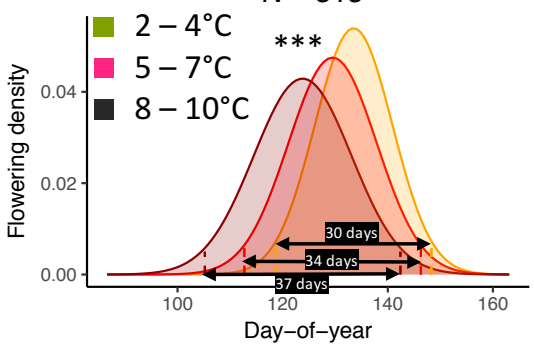

Aesculus hippocastanum

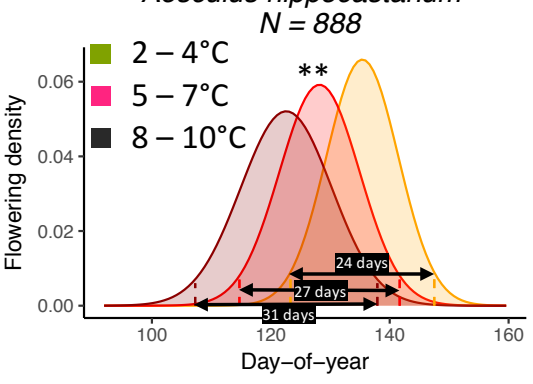

Calluna vulgaris

$N=1022$

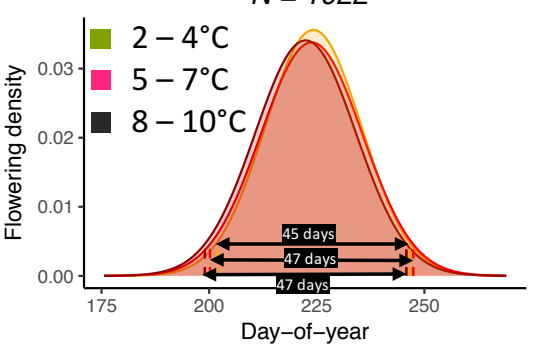

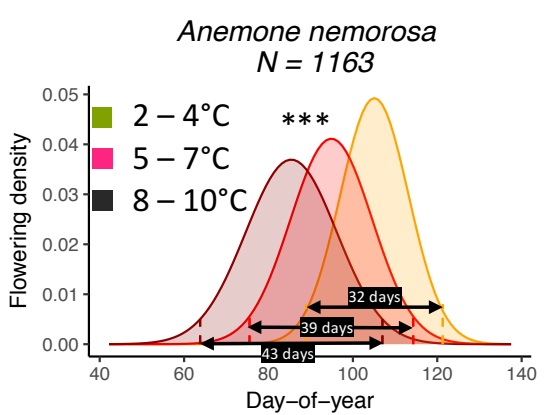

Corylus avellana

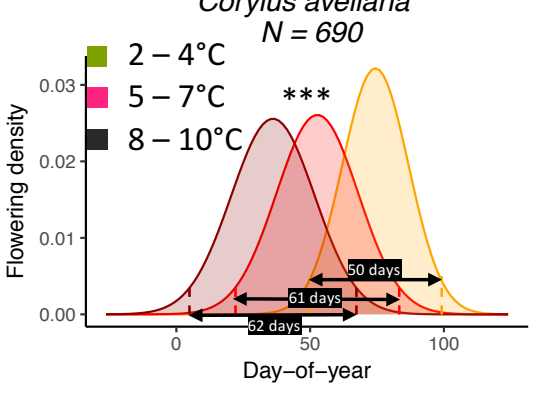

Fraxinus excelsior $N=706$

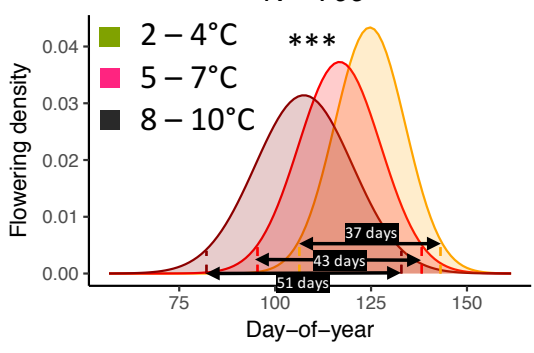

Syringa vulgaris
$N=1001$

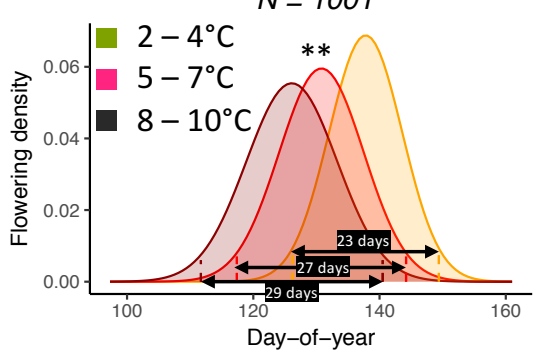

Sorbus aucuparia $N=988$

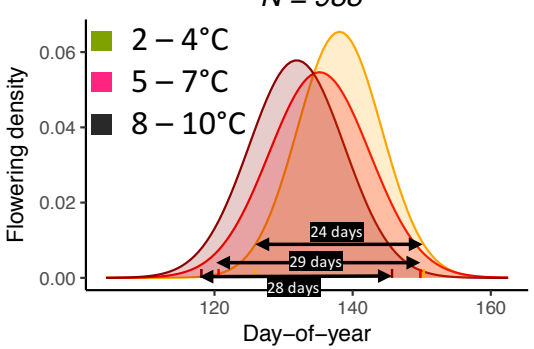


Figure S4 | The effect of preseason temperature on inter-individual (within population) flowering distributions. $N=$ Number of available year $\mathrm{x}$ site $\left(1^{\circ} \mathrm{x} 1^{\circ}\right.$ areas $)$ combinations. To model the distributions (means and standard deviations), mixed-effects models were applied including site as a random effect. Stars indicate a significant positive effect of preseason temperature on FLS $(* P<0.05 ; * * P<0.01 ; * * * P<0.001)$. Black arrows show the period in which $>95 \%$ of individuals flower (4 standard deviations), e.g., for Alnus glutinosa, in years with a cool preseason, $95 \%$ of individuals within a population flower within 44 days, whereas in years with a warm preseason this period is 67 days (52\% longer). 

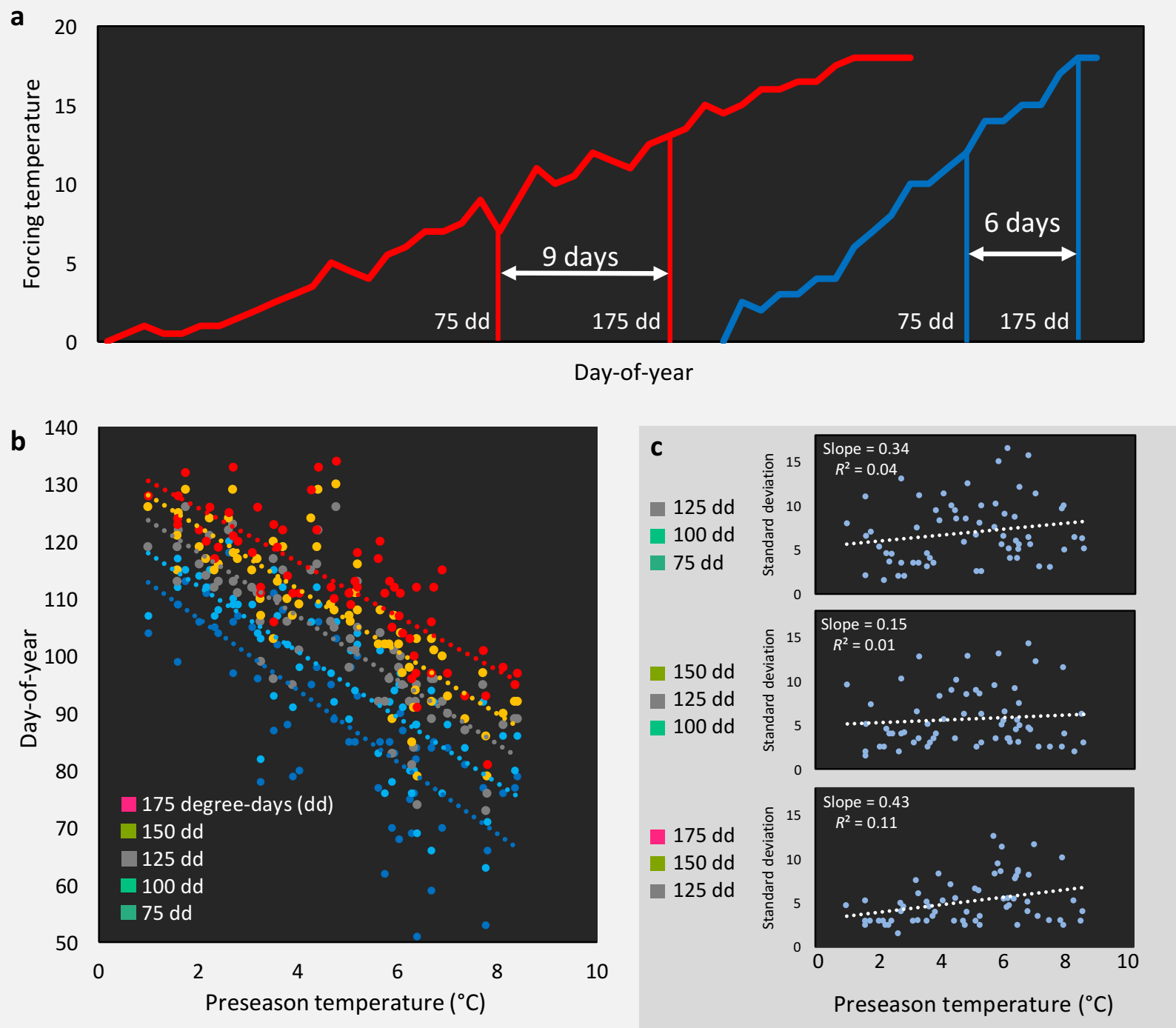

Figure S5 | Does decreased LOS and FLS under climate warming result from a decrease in within-spring warming speed? a, Schematic representation of the hypothesized relationship between climate warming and within-spring temperature increase (see refs. 14,15): in a cold year (blue line) temperature rises late but fast, in a warm year (red line) temperature rises early but more slowly (flattening the temperature curve during spring). The result would be a less synchronized phenology in warm years, because forcing sums required for the occurrence of the respective phenological event are more spread out. This is illustrated by the date (day-of-year) at which 75 or 175 degree-days (cumulative daily temperature above $5^{\circ} \mathrm{C}$ starting 1 of January) accumulate in both cases (difference of 9 day in the warm year vs. 6 days in the cold year). b, The day of year when $75,100,125,150$, or 175 degree-days have accumulated, shown as response to mean preseason temperature (14 Feb until 15 April) in the respective year, using temperature data for 63 years (1955-2017) from Munich, Germany. c, The standard deviations of the dates (days of year) when (i) 75, 100, and 125 degree-days have accumulated (upper panel), (ii) 100, 125, and 150 degree-days have accumulated (middle panel), and (iii) 125, 150, and 175 degree-days have accumulated (middle panel) in response to preseason temperature. 
Leaf-out

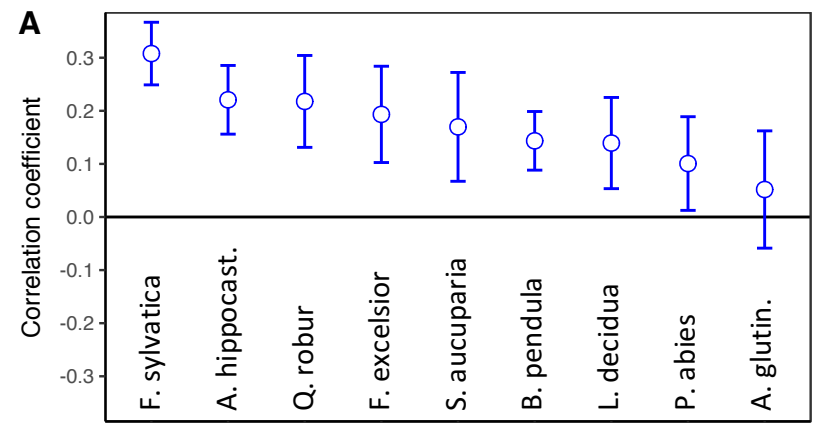

B
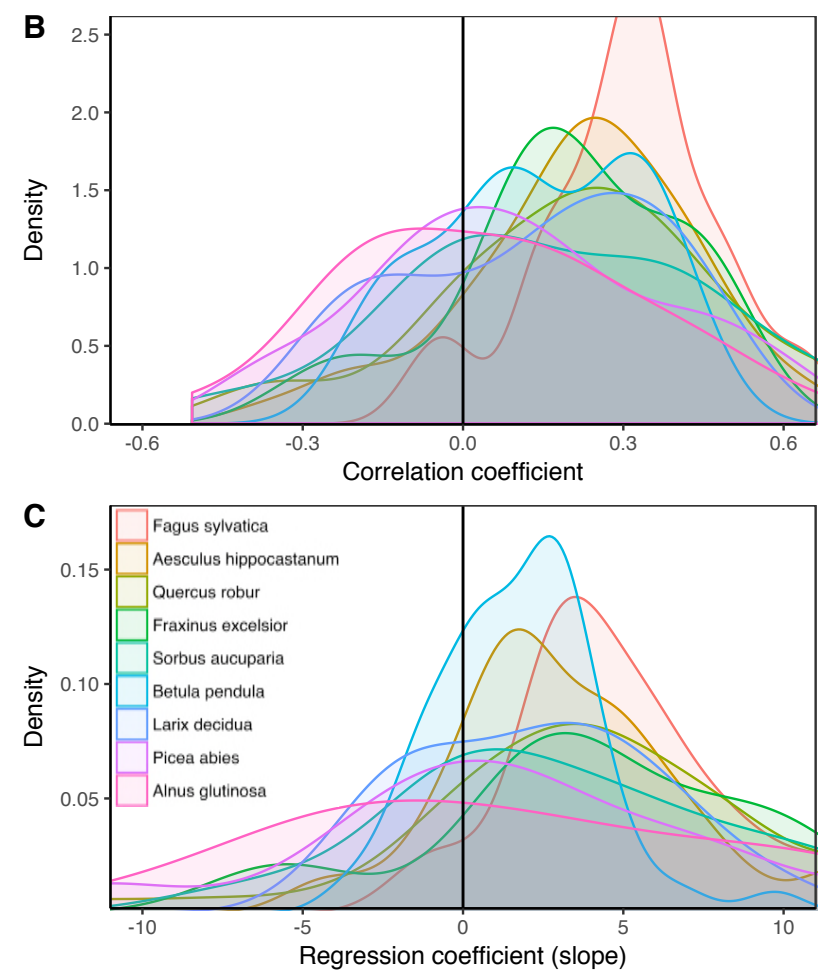

Flowering
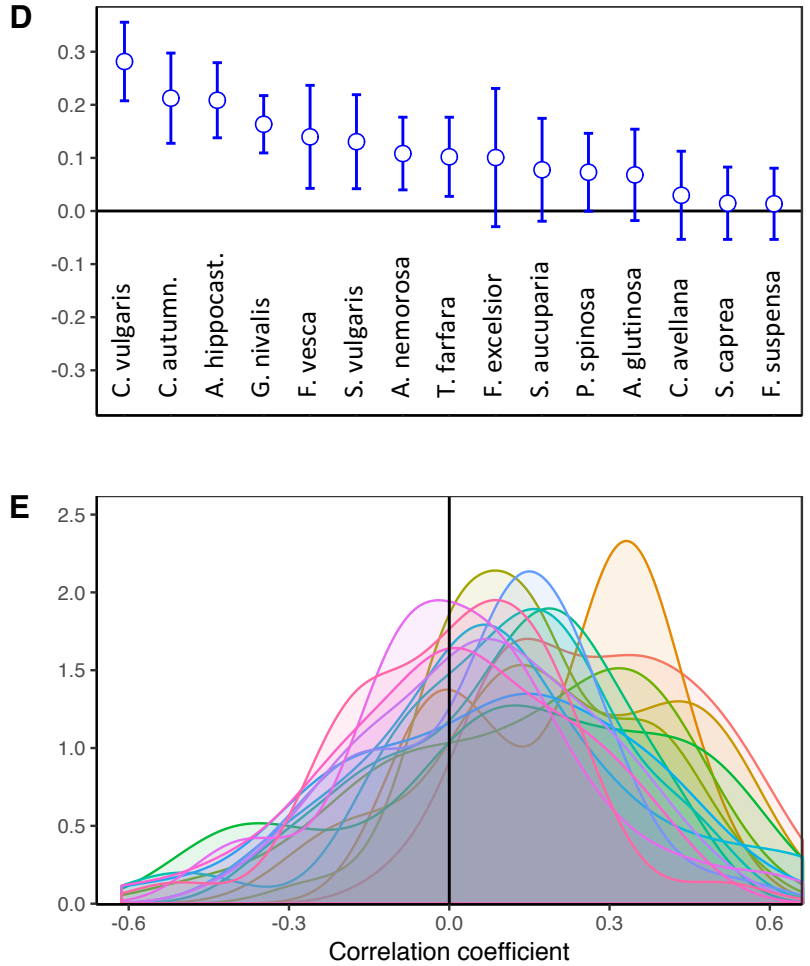

$\mathbf{F}$

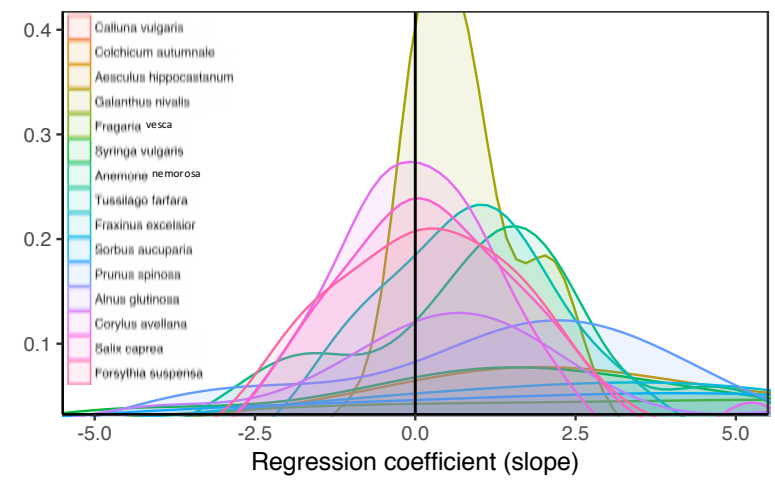

Figure S6 | Greater variation of forcing requirements among individuals with increasing preseason temperatures. Effects of preseason temperature on inter-individual LOS-DD (A-C) and FLS-DD (D-F), using PEP data. A, Mean Pearson correlation coefficients $( \pm 95 \%$ confidence intervals) for the effect of spring temperature on LOS-DD. See Figs. S1b and S2b for number of sites $\left(1^{\circ} \times 1^{\circ}\right.$ areas) in which the relationship was analysed. B, C, Density plots of regression (B) and Pearson correlation coefficients $(\mathrm{C})$ between LOS-DD and spring temperature for nine species. Regression coefficients show the change in LOS-DD per each degree increase in spring temperature. D-F, Same plots for the effect of spring temperature on FLS-DD. LOS-DD = Standard deviation of inter-individual forcing requirements until leaf-out; FLS-DD = Standard deviation of inter-individual forcing requirements until flowering. 
a

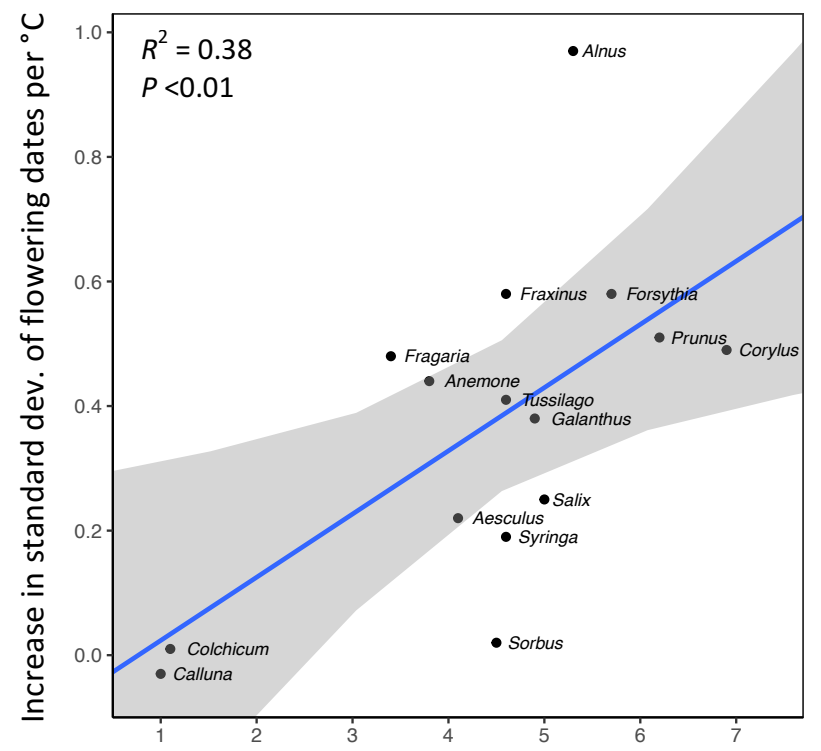

Advance in flowering date per one degree warming b

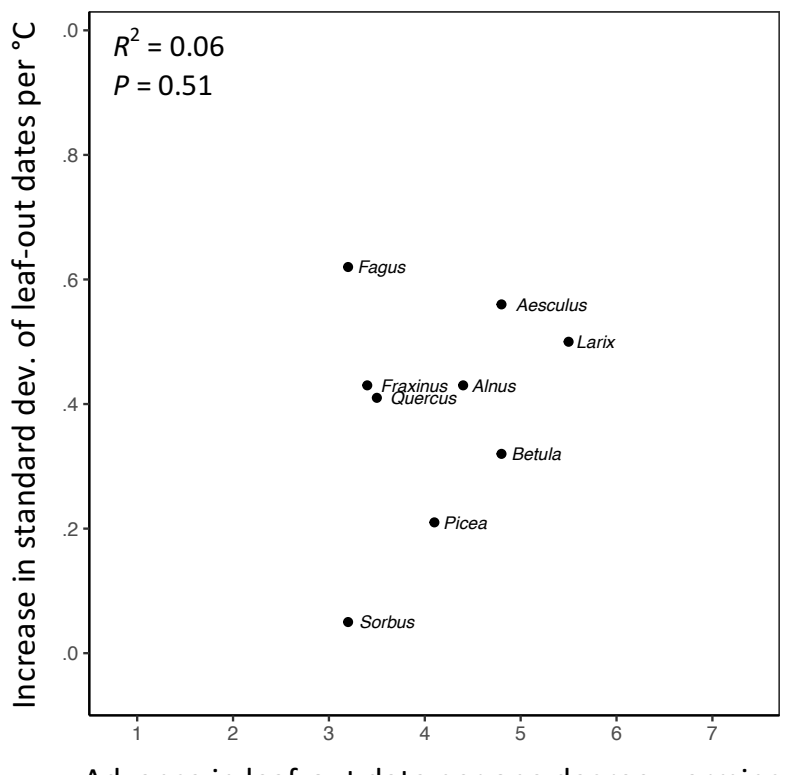

Advance in leaf-out date per one degree warming

Figure S7 | In species in which preseason temperature has little effect on the mean flowering date, preseason temperature also has little effect on FLS. a, Positive correlation between species' mean temperature sensitivity of flowering date (days advance in flowering per one degree warming) and the mean temperature sensitivity of FLS (increase in the standard deviation of inter-individual flowering times per one degree warming). b, No correlation between species' mean temperature sensitivity of leaf-out date (days advance in leaf-out per one degree warming) and the mean temperature sensitivity of LOS (increase in the standard deviation of inter-individual leaf-out times per one degree warming). The effects of preseason temperature on mean flowering date, mean leaf-out date, FLS, and LOS were inferred from mixed-effects models including site as a random effect. Species: Alnus glutinosa, Aesculus hippocastanum, Anemone nemorosa, Betula pendula, Corylus avellana, Colchicum autumnale, Calluna vulgaris, Fraxinus excelsior, Forsythia suspense, Fagus sylvatica, Fragaria vesca, Galanthus nivalis, Larix decidua, Picea abies, Prunus spinosa, Quercus robur, Sorbus aucuparia, Salix caprea, Syringa vulgaris, Tussilago farfara. 


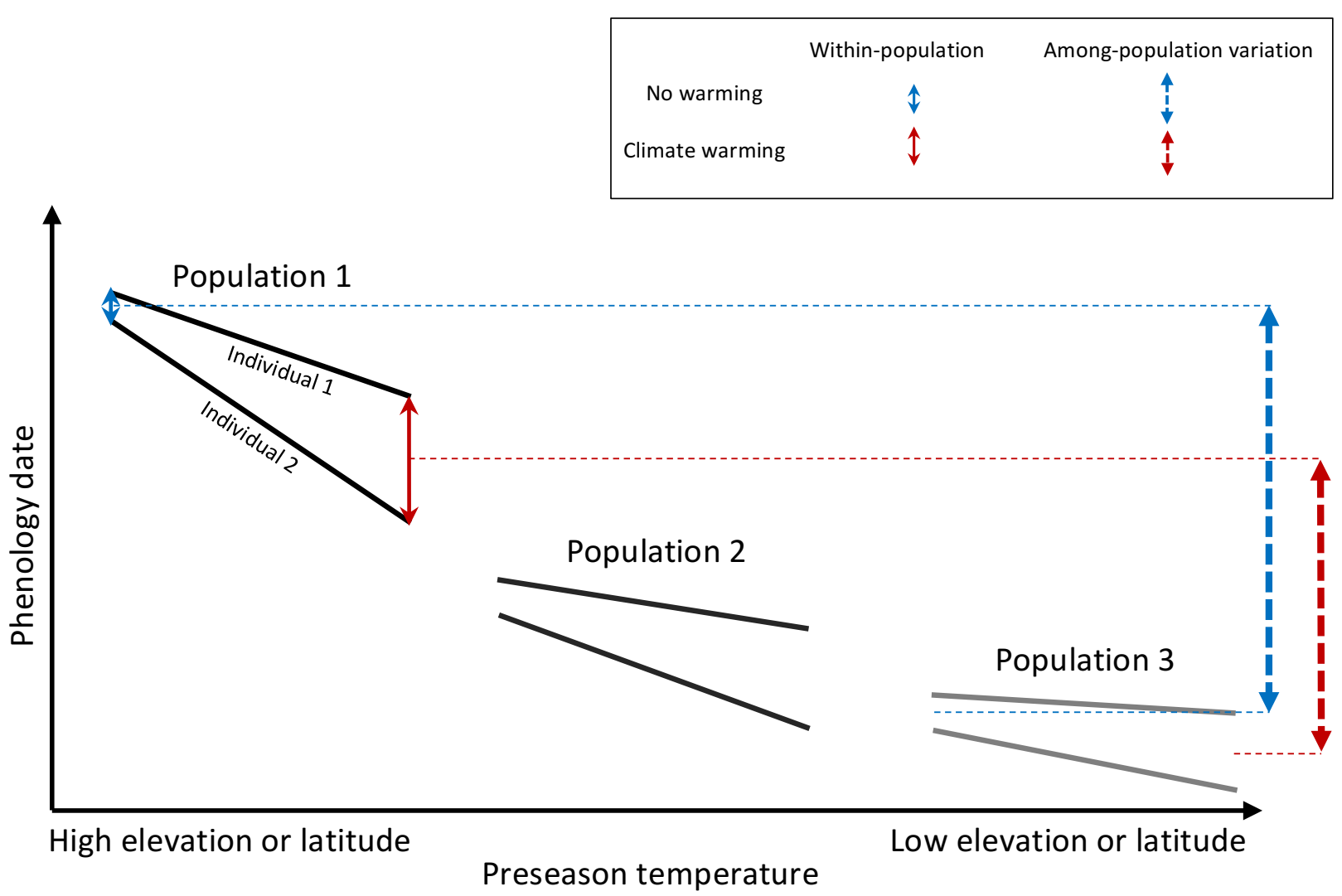

\section{Figure S8 | Schematic representation of within- and among-population phenological} synchrony in response to climate warming. As demonstrated in this study, inter-individual synchrony within a population will decrease under warmer preseason temperatures because individuals differ in their sensitivity to temperature. Within-population variation under ambient or warmed preseason temperatures is illustrated by the solid blue and red arrows, respectively. By contrast, phenological synchrony among populations is expected to increase, given that populations in warm regions (Population 3) will advance their phenology less than populations in cold regions (Population 1). This is illustrated by the dashed blue and red arrows, showing that the difference in the average phenological date between Population 1 and 3 is smaller under warmer preseasons (red dashed arrow) than under ambient preseason temperatures (blue dashed arrow). 


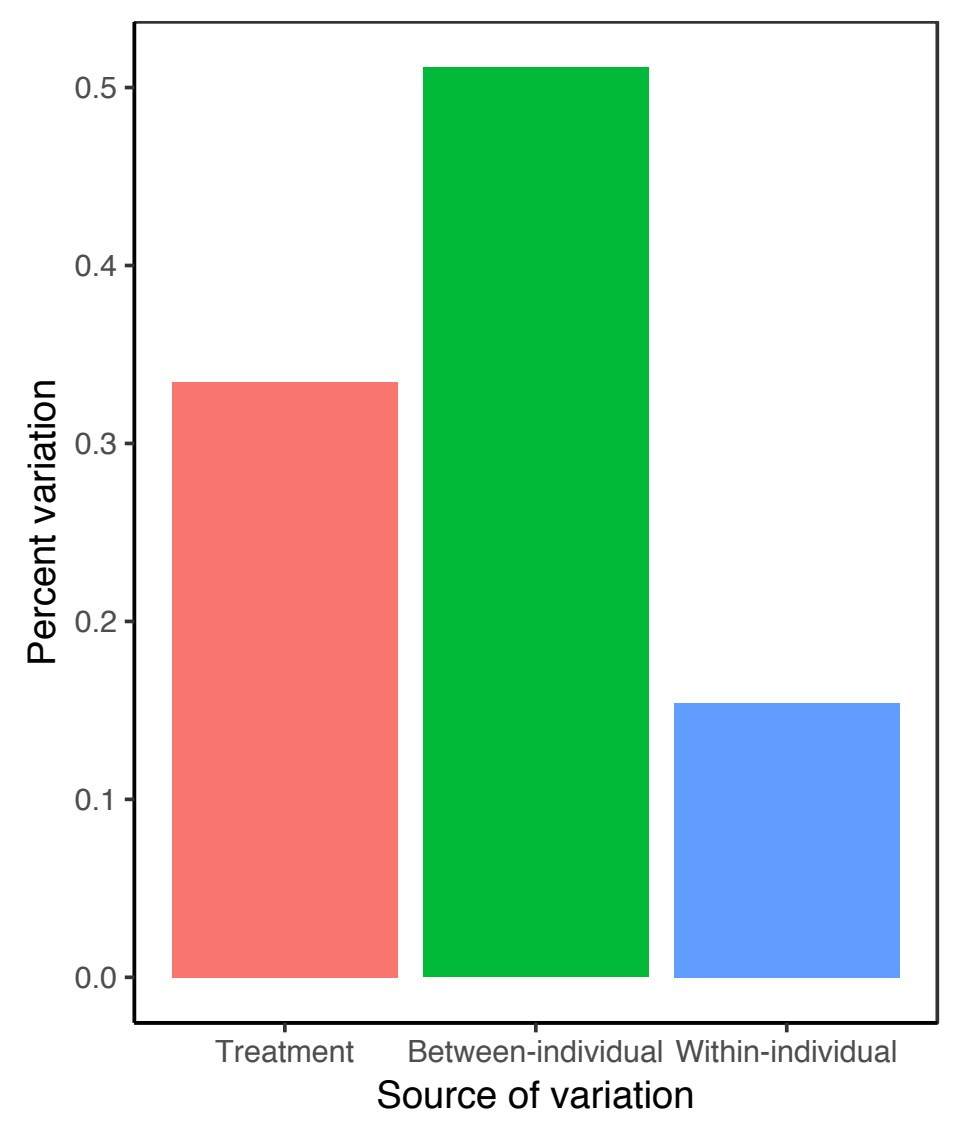

Figure S9 | Percent variation in leaf-out dates attributable to treatment effects and between- and within-individual variation within treatments. Data from experiment 2 (see Methods). Variance components were inferred from random-effects-only models, including leafout date as the dependent variable and treatment and individuals as nested random effects. 